\title{
Concepciones y Prácticas Evaluativas de los Docentes del Área Curricular de CTA en las II. EE. Públicas de Educación Secundaria de Arequipa (Perú)
}

\section{Osbaldo Turpo Gebera}

\author{
I.E. 41515 Reino de España, Camaná, Arequipa y \\ Universidad de Deusto, España
}

Osbaldo Turpo Gebera es Profesor de Educación Secundaria en Biología y Química, graduado en el Instituto Superior Pedagógico Arequipa; Magister en Administración de la Educación por la Universidad Católica de Santa María; ha realizado estudios de Máster en Psicología en la Universidad del País Vasco (España); y un Doctorado en Educación en la Universidad Nacional Mayor de San Marcos.

Ha laborado como docente en diversas Instituciones Educativas de Arequipa (Perú), sido Becario de la Asociación Universitaria Iberoamericana de Postgrado (AUIP), de la Organización de Estados Iberoamericanos, (OEI), Ex becario de Cooperación por la Universidad de Salamanca, y actual Becario Erasmus Mundus en la Universidad de Deusto (España).

Sus áreas de investigación incluyen la evaluación educativa, TIC y educación, identidad docente, entre otros temas. 


\title{
Concepciones y Prácticas Evaluativas de los Docentes del Área Curricular de CTA en las II. EE. Públicas de Educación Secundaria de Arequipa (Perú)
}

\begin{abstract}
Resumen
Los profesores ${ }^{1}$ del área curricular de Ciencia, Tecnología y Ambiente (CTA), en el curso de sus intervenciones pedagógicas, revelan un conjunto de concepciones y prácticas evaluativas no siempre concordantes con los propósitos de renovación educativa. En su ser y quehacer docentes, coexisten pensamientos y acciones que responden a discursos y rutinas internalizadas por la formación continua del docente. Específicamente, conviven posicionamientos evaluativos alineados con los "tradicionales", tales como finalidades evaluativas centradas en la aprobación de los logros de aprendizaje (rendimiento) con las funciones simbólicas de la evaluación que priorizan el uso de la normatividad vigente, la prevalencia de los contenidos conceptuales sobre los demás, la recurrencia a procedimientos evaluativos centrados en las capacidades resolutivas y expositivas, en desmedro de otros medios y recursos fundados en la observación y reflexión, y una exclusiva responsabilidad del docente como evaluador; junto a posturas "modernas", como referente en torno al cual se estructuran las demás, una preferencia por una evaluación procesual extensiva y recuperadora de otras modalidades, relegando a la evaluación normativa y optando por una criterial.

Palabras clave: enseñanza secundaria, enseñanza de las ciencias, evaluación del aprendizaje, docente de secundaria, responsabilidad del docente
\end{abstract}

1 Al referirnos a los profesores también incluimos a las profesoras en los mismos términos. El uso gramatical no esconde una discriminación sexista (Eco, 1998). 


\title{
Teachers' Evaluation Concepts and Practices in STE Curricular Area in Public Secondary Schools in Arequipa (Peru)
}

\begin{abstract}
Teachers in the curricular area of Science, Technology and Environment (STE), in the course of their educational interventions, reveal a set of conceptions and assessment practices that are not always consistent with the purposes of educational renewal. In their being and acting, teachers have thoughts and actions that respond to speeches and internalized routines because of their continuous training. Specifically, there are "traditional" ways of evaluating, such as evaluative purposes focusing on the adoption of learning goals (achievement) with the symbolic functions of evaluation, prioritizing the use of current regulations, the prevalence of conceptual contents over others, the recurrence of evaluation procedures focused on solving and expository capacities, but in detriment of other resources based on observation and reflection, and teacher responsibility as an evaluator; along with "modern" postures that act as reference to the others, a preference for an extensive assessment, relegating normative evaluation and adopting a criterial one.
\end{abstract}

Keywords: Secondary Education, science education, learning assessment, secondary teacher, teaching responsibility 


\section{Introducción}

a evaluación educativa posibilita "determinar el grado de eficacia de los

sistemas educativos y mejorar la calidad de la educación, obedece también a la importancia otorgada en la sociedad actual al uso de la evaluación para demostrar en qué medida han sido logrados los objetivos educativos" (LLECE, 2008, p. 40).

Por ende, investigar sobre la evaluación educativa y, por lo tanto, la evaluación del aprendizaje en ciencias, resulta una invitación irresistible, pero bajo derroteros que enfaticen la exploración interna de por qué ocurre; incidiendo en el cómo y evitando caer en la tentación de desarrollar un discurso a la vez complejo y abstracto.

Efectivizar dicha propuesta supuso reducir el foco de atención a las concepciones y prácticas evaluativas de los docentes del área curricular de Ciencia, Tecnología y Ambiente (CTA). Es decir, reconocer los procesos docentes por los cuales discriminan, valoran, critican, fundamentan, enjuician, optan, entre lo que consideran que tiene un valor en sí y aquello que carece de él. Estos posicionamientos revelan la variedad de constructos formulados en el decurso de su vida socioprofesional, del que se tiene escaso conocimiento y, sí, muchas afirmaciones sin el valor del sustento que imprime la investigación.

En ese sentido, en esta investigación se identifican las variadas concepciones y prácticas evaluativas sostenidas por los docentes, no siempre concordantes con los propósitos de innovación educativa, sino en muchos casos, aún ajustadas a prácticas "tradicionales"; revelando la ineficacia de los procesos de capacitación docente y el desconocimiento docente de los propósitos de las políticas educativas, que tienden a buscar nuevas formas pedagógicas en el ser y quehacer docentes.

Este tipo de situaciones plantea, además de hurgar en la pervivencia de una peculiar dinámica evaluativa, inferir posibilidades para introducir más asertivamente las propuestas de evaluación educativa; ello, a partir de lo que el docente considera como útil a su tarea educativa, criterio internalizado y cuyo cambio resultará complejo y poco claro para él sino percibe el sentido de aplicabilidad y su identificación con las nuevas formas pedagógicas. Así, resulta conveniente generar las transiciones educativas necesarias, asumiendo que es factible revertir ciertas concepciones y prácticas si se presentan alternativas que resulten más funcionales y operativas a las actuales.

162 I De no percibirse y sentirse ello, es probable que el cambio no se opere o 
convivan propuestas pedagógicas disjuntas sin mayor transcendencia para el mejoramiento.

\section{Problema Estudiado}

Animado por tales inquietudes, se emprendió una aproximación sistemática a las concepciones y prácticas hegemonizadas por los docentes en la evaluación del aprendizaje del área de CTA; para así aportar al develamiento sobre la continuidad de ciertas formas y maneras de evaluar, a pesar de los "buenos" propósitos de las reformas educativas.

\section{Hipótesis}

Las diversas concepciones y prácticas evaluativas de los docentes del área curricular de CTA están fundadas en supuestos más o menos explícitos y en rutinas más o menos implícitas, asociadas a un discurso y ejercicio pedagógico sin mayor renovación.

\section{Planteamientos Teóricos}

La evaluación sugiere una acción reflexiva y crítica, lo mismo que una revisión de su doctrina y teorías, incluyendo la política, retórica y ética, tanto como las técnicas y los recursos utilizados en los distintos ámbitos del quehacer educativo-social, puesto que representa la columna medular de "todo cambio o innovación, de cualquier modelo, de cualquier metodología. Y, que al mismo tiempo, sigue siendo una de las actividades docentes que más planteamientos, dificultades y dudas continúa generando" (Zaragoza, 2003, p. 3).

En ese sentido, la "línea de investigación del pensamiento y acción docente" proporciona una aproximación a su entendimiento.

\section{"Pensamiento y Acción del Docente"}

El marco explicatorio de esta línea no es reciente, se viene consolidando desde los años sesenta, formalizada a partir de 1975 en el Institute for Research 
on Teaching (Universidad de Michigan), cuando la comunidad científica acepta el modelo (Clark, 1978).

En el contexto hispanohablante adquiere una doble denominación: "Paradigma Mediacional centrado en el Profesor" (Pérez, 1988) y "Paradigma del Pensamiento del Profesor" (Marcelo, 1987). En ambas connotaciones, el educador es considerado un sujeto racional y reflexivo, que enjuicia y decide en su actividad docente.

Sus objetivos primarios buscaban describir la vida mental del profesor, asumiéndolos como profesionales racionales que realizan juicios y ejecutan decisiones en un entorno complejo e incierto, guiados por sus pensamientos, juicios y decisiones (Pérez, 1988). En esencia, no es un autómata en sus clases, menos un mero técnico que aplica ciertas recetas en contextos similares, de acuerdo con unos repertorios adquiridos (racionalidad técnica), sino un profesional reflexivo, protagonista consciente de sus decisiones educativas.

El paradigma, en su dinámica evolutiva, considera: a) un modelo de toma de decisiones, donde el profesor es quien valora situaciones, procesa la información, toma decisiones sobre qué hacer, guía actuaciones y observa los efectos de las acciones; y b) un modelo de procesamiento de la información, a partir del cual adquiere, transforma, almacena y utiliza la información (Mahoney, 1974).

De esa manera, se reconocen los dominios de participación educativa: a) los procesos de pensamiento del profesor ("en la cabeza de los docentes" y no observables), y b) las acciones del docente y sus efectos observables (medidos con más facilidad y sujetos a la comprobación empírica), revelando la naturaleza interactiva del pensamiento y acción.

Sucesivas investigaciones demostraron la compartición de procesos cognitivos comunes durante la activación de los modelos, como un todo unitario; pues, al transitar desde la cognosis a la reflexividad, aparecen operando conexamente más que disjuntos, secundándose en relaciones recíprocas de intercambio (Marsellés, 2003).

El docente, al enfrentarse a una situación compleja, crea un modelo mental simplificado y manejable, y se comporta racionalmente estableciendo diferentes modos de estructurar y organizar una actuación, atendiendo la diversidad de pensamientos adquiridos y configurados sucesivamente; o, en sentido inverso, recuperando ideas, creencias, teorías implícitas, etc. a partir de su puesta en operatividad. En ese proceder, comprueba las características de la situación y sus cambios, procesa la información del contexto, decide las intervenciones, reorienta las decisiones tomadas y observa y valora el efecto de sus actuaciones sobre sus alumnos (Shavelson y Stern, 1983). 


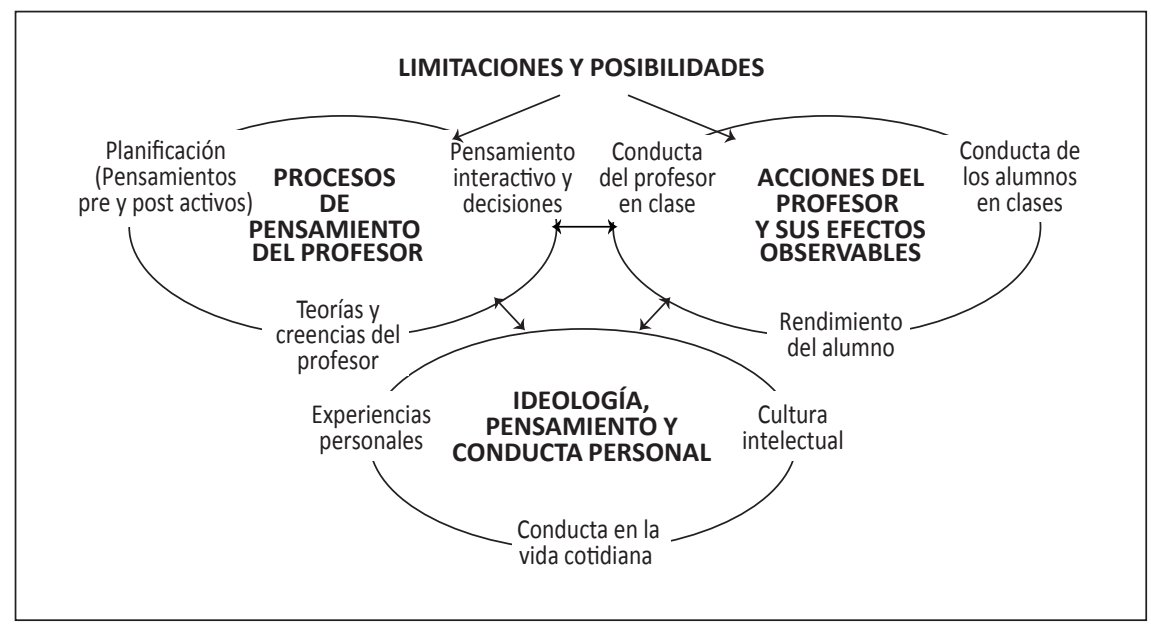

Figura 1. Modelo de Clark y Peterson (citado en Gimeno, 1998).

En el decurso del proceso educativo, los profesores planifican según el tiempo y volumen de la materia a programar; estructuran y organizan unidades didácticas siguiendo diversas concepciones y prácticas; muchas de las cuales devienen en:

- $\quad$ Rutinas pedagógicas: alivian el volumen de decisiones conscientes, permitiendo atender y observar el flujo real de los acontecimientos.

- Decisiones de intervención: al observar irrupciones o distorsiones en sus estrategias y rutinas, planificadas o no, suscitan una adaptación del modelo planificado a los aspectos de la situación concreta.

- $\quad$ Entre sus funciones, según Pérez y Gimeno (1988), destacan:

- Corregir y ajustar la estrategia planificada.

- Afrontar aspectos y situaciones imprescindibles en principio.

- Regular el comportamiento de acuerdo con ciertos principios didácticos.

- Adaptar las tareas a los diferentes alumnos.

En cualquier situación, el docente se debate entre una serie de juicios, decisiones y propuestas que derivan del modo de interpretar las intervenciones, por lo que su comprensión no solo transita por conocer los procesos formales y las estrategias de procesamiento de información o toma de decisiones, sino por escudriñar en la red ideológica de las teorías y creencias que determinan su sentido sobre el mundo en general y su práctica docente en particular. 
En ese quehacer, se reconoce el influjo determinante del sustrato ideológico, omnipresente en los procesos de pensamiento y acción del profesor. Cuanto más complejo, fluido y cambiante es el escenario de la práctica pedagógica, más decisivo se presenta el "rico almacén de conocimientos generales sobre los objetos, personas, acontecimientos, relaciones peculiares [...], que cada hombre ha construido a lo largo de su experiencia, en particular de su experiencia profesional" (Nisbet y Ross, 1980, citados en Pérez y Gimeno, 1988 , p. 44). Pero, no es solo el sustrato ideológico el que regula las intervenciones docentes, lo hace también el "conocimiento práctico", adquirido en la experiencia como conocimiento proposicional explícito, bien organizado y articulado lógicamente. Todos ellos gravitan de modo más o menos indefinido, paradójico e irracional en sus intercambios; incluyendo las interpretaciones reflejas derivadas socialmente que orientan las acciones cotidianas ("teorías implícitas"; Janesick, 1977).

Los profesores no son observadores indiferentes en el aula, sino son agentes interesados, vitalmente implicados en el flujo de intercambios simbólicos del grupo psicosocial del aula, lo que supone aceptar responsabilidades sociales por la calidad de sus intervenciones, siendo valorado en función de sus efectos y en el desarrollo de sus alumnos, que sesgan inevitable y sistemáticamente el sentido del profesor en los éxitos y fracasos estudiantiles. Su actividad no es lineal ni casual, sino una actividad intencional, cargada de valores, en un medio psicosocial de interinfluencias, donde los actores interpretan y proyectan su particular mundo de significados construidos (Gimeno y Pérez, 1995).

En el proceso de la enseñanza-aprendizaje es notorio el carácter incierto e imprevisible, así como la naturaleza problemática y frecuentemente conflictiva de los intercambios que la caracterizan, haciendo cuestionable la opción didáctica adoptada en virtud de los valores priorizados. En ese proceder, cada quien se comporta conforme al sustrato de ideas y sentimientos que configuran sus intervenciones.

La actividad profesional docente es de una "conversación reflexiva" con la situación del problema, en un entorno complejo, incierto y ambiguo, y de implicación, indagación y ensayo como actor y receptor sobre el saber que ofrece y la actuación que realiza, afectado por la estructura de las tareas académicas y por el clima psicosocial del medio escolar, que los sitúa dentro de ámbitos, como argumenta Schön (1992):

- Persona-profesores con estructuras cognitivas rígidas, pobres y poco diferenciadas, que intentan mantener invariables sus esquemas en contra de 
potentes evidencias contrarias al medio. Incluso, reconociendo el carácter contraproducente de su ineficacia, negarán o distorsionarán la información que no encaje con sus previsiones.

- Persona-profesores con estructuras mentales y redes semánticas amplias; buscan la extensión, diferenciación e integración de estímulos e informaciones de fuentes dispares y diversas; quiebran el egocentrismo mental y se abren a las sucesivas reformas de sus esquemas, generadas por los cambios y la evolución de sus vivencias.

En síntesis, es manifiesta la interacción recíproca del pensamiento y la acción de los docentes en un entorno ecológico concreto: la intervención pedagógica en el aula, donde se revelan las diversas decisiones asumidas en: a) los aspectos técnicos del actuar (instrumentos y estrategias adaptadas a una situación), y en b) los aspectos morales de la acción, es decir, normas, usos y prohibiciones (Schwab, 1983).

\section{Evaluación del Aprendizaje en Ciencias}

Los profesores organizan sus estrategias y estilos de enseñanza-aprendizaje

[...] situándolos en un contexto y poniendo los problemas en perspectiva, de manera que el alumno pueda establecer el nexo entre su solución y otras interrogantes de mayor alcance. El profesor se convierte en mediador del acto didáctico; y mediador significa mediar entre el discente y los contenidos; de modo que las estrategias y estilos de enseñanza repercuten en el rendimiento académico del estudiante. Su papel no se reduce a la transmisión de conocimientos, sino que se orienta a la formación integral de los educandos. (Salvador, 1994, pp. 71-72)

En la enseñanza-aprendizaje del área de CTA se hace evidente que

[...] hacer ciencia no se ajusta a ningún "método" preciso, a ningún algoritmo de etapas claramente definidas. El consenso general transita por que la esencia de la orientación científica - lejos de toda idea de "método" - se encuentra en el cambio de un pensamiento y acción basados en las "evidencias" del sentido común a un razonamiento en términos de hipótesis, a la vez más creativo (ir más allá de lo evidente, 
imaginando nuevas posibilidades) y más exigente (fundamentar y someter a prueba las hipótesis, dudar del resultado y buscar la coherencia global). (Gil y Martínez, 1999, p. 19)

La docencia es un proceso que pone a prueba destrezas y conocimientos "seguros", su aplicabilidad deviene de un proceso conducido y determinado por las situaciones implicadas en la construcción del conocimiento. Estas decisiones los sitúan ante los paradigmas pedagógicos predominantes en el escenario educativo nacional: el conductismo, cognitivismo y el constructivismo; que coexisten, muy a pesar de los cambios promovidos por las capacitaciones docentes; que, en lugar de esclarecer los propósitos pedagógicos, devienen en confusiones y desconocimientos que llevan a ejecutar una práctica educativa con dudas e improvisación (Arroyo, 2007).

Propiamente, en la didáctica de las ciencias, cada modelo didáctico se sintetiza en la Tabla 1.

Cada modelo está signado por características distintivas que hacen estimables las discrepancias. Por ejemplo, en torno al aprendizaje. Para el conductismo, su fundamentación tiene una base empírica, precisa de una contrastación para su objetivación, es decir, su carácter de "verdad" no depende del sujeto que la observa y analiza; esto lo sitúa dentro de la perspectiva epistémica del empirismo, donde "el conocimiento comienza con la experiencia y, que al mismo tiempo, ésta es su prueba de verdad. [...] en el sentido que las leyes teóricas son inducidas de la experiencia" (Flores, Gallegos y Reyes, 2007, p. 364). En tanto que, para el constructivismo, el conocimiento es resultado de una interacción social entre sujeto-objeto, perennemente resignificado en función de la posición prevalente, quien finalmente valida su "veracidad"; que lo sitúa en una visión epistemológica del relativismo, en el que

[...] el conocimiento es construido por sujetos y comunidades y que ese conocimiento constituye esquemas representacionales transformables conceptual y estructuralmente. Considera a los fenómenos como algo a ser interpretado y el proceso de validación está dado por la comunidad científica. (Flores et al., 2007, p. 364)

Situándonos en el plano de la evaluación del aprendizaje y de las orientaciones epistemológicas, en el conductismo se evalúa lo observable, reflejado en una conducta verificable (medición), es decir, en la adquisición de saberes 168 I y destrezas contrastables, rubricando el carácter empírico de la evaluación, 
Tabla 1

Modelos Didácticos Utilizados por los Docentes de Ciencias

\begin{tabular}{|c|c|c|c|}
\hline & Conductismo & Cognitivismo & Constructivismo \\
\hline $\begin{array}{l}\text { 1. Origen del } \\
\text { conocimiento }\end{array}$ & $\begin{array}{l}\text { Toma de conciencia } \\
\text { de una realidad } \\
\text { estructurada }\end{array}$ & $\begin{array}{l}\text { No separado del } \\
\text { sujeto, que al actuar } \\
\text { transforma el objeto } \\
\text { de conocimiento, } \\
\text { y construye } \\
\text { sus propias } \\
\text { interpretaciones. }\end{array}$ & $\begin{array}{l}\text { Producto de } \\
\text { la interacción } \\
\text { dialéctica entre el } \\
\text { sujeto cognoscente } \\
\text { y el objeto, en } \\
\text { un contexto de } \\
\text { negociación social } \\
\text { de significados }\end{array}$ \\
\hline $\begin{array}{l}\text { 2. Desarrollo del } \\
\text { conocimiento } \\
\text { científico }\end{array}$ & $\begin{array}{l}\text { Es acumulativo. } \\
\text { Un cuerpo de } \\
\text { conocimientos } \\
\text { acabados y } \\
\text { objetivamente } \\
\text { probados }\end{array}$ & $\begin{array}{l}\text { En continuo proceso } \\
\text { de elaboración, } \\
\text { revisión y } \\
\text { reconstrucción }\end{array}$ & $\begin{array}{l}\text { Fruto de sucesivas } \\
\text { rectificaciones } \\
\text { condicionadas por } \\
\text { el pensamiento } \\
\text { dominante de la } \\
\text { época }\end{array}$ \\
\hline $\begin{array}{l}\text { 3. Carácter de } \\
\text { la actividad } \\
\text { científica }\end{array}$ & $\begin{array}{l}\text { Procura verdades } \\
\text { objetivas, neutras, } \\
\text { externas al individuo } \\
\text { que las observa y } \\
\text { analiza }\end{array}$ & $\begin{array}{l}\text { Influye el contexto } \\
\text { particular, } \\
\text { conteniendo } \\
\text { componentes } \\
\text { subjetivos }\end{array}$ & $\begin{array}{l}\text { Influye el contexto } \\
\text { social, que } \\
\text { posibilita no solo } \\
\text { la producción, sino } \\
\text { la validación del } \\
\text { conocimiento }\end{array}$ \\
\hline $\begin{array}{l}\text { 4. Concepción } \\
\text { del aprendizaje } \\
\text { y enseñanza } \\
\text { de la ciencia } \\
\text { (perspectiva } \\
\text { epistémica) }\end{array}$ & $\begin{array}{l}\text { Expresa un } \\
\text { cambio estable } \\
\text { en la conducta. } \\
\text { Los saberes son } \\
\text { transmitidos en una } \\
\text { formación rígida } \\
\text { y estructurada } \\
\text { (Empirismo) }\end{array}$ & $\begin{array}{l}\text { Confrontación de } \\
\text { ideas previas con el } \\
\text { conocimiento nuevo, } \\
\text { aproximado por el } \\
\text { maestro, libros, etc. } \\
\text { (Racionalismo) }\end{array}$ & $\begin{array}{l}\text { Enfatiza la necesidad } \\
\text { de la interacción } \\
\text { social y del papel } \\
\text { del lenguaje en } \\
\text { contextos escolares } \\
\text { (Relativismo) }\end{array}$ \\
\hline $\begin{array}{l}\text { 5. Papel del } \\
\text { conocimiento } \\
\text { previo }\end{array}$ & $\begin{array}{l}\text { Si coincide con } \\
\text { las ideas válidas; } \\
\text { si no, se descarta } \\
\text { por erróneo, } \\
\text { procediéndose a su } \\
\text { corrección }\end{array}$ & $\begin{array}{l}\text { Participa del } \\
\text { despliegue de } \\
\text { estrategias que } \\
\text { favorezcan el cambio } \\
\text { conceptual }\end{array}$ & $\begin{array}{l}\text { Debe desecharse, } \\
\text { pues no existe } \\
\text { continuidad entre } \\
\text { concepciones } \\
\text { alternativas y } \\
\text { conceptos científicos }\end{array}$ \\
\hline $\begin{array}{l}\text { 6. Evaluación del } \\
\text { aprendizaje }\end{array}$ & $\begin{array}{l}\text { Evalúa la conducta } \\
\text { observable y sus } \\
\text { condiciones. Mide el } \\
\text { grado de ejecución } \\
\text { del conocimiento y } \\
\text { habilidades }\end{array}$ & $\begin{array}{l}\text { Se centra menos en } \\
\text { el producto y más } \\
\text { en los procesos e } \\
\text { interpretaciones, en } \\
\text { y la significatividad } \\
\text { del aprendizaje }\end{array}$ & $\begin{array}{l}\text { Evalúa, } \\
\text { adicionalmente, } \\
\text { las habilidades, } \\
\text { la colaboración } \\
\text { y capacidad } \\
\text { argumentativa }\end{array}$ \\
\hline
\end{tabular}


cuyo "propósito [es] recoger los resultados finales del proceso y valorar la eficacia del mismo en función de los porcentajes de obtención de los objetivos prefijados" (Domínguez y Diez, 1996, p. 351). Para el cognitivismo y constructivismo, importa menos el producto final, e inciden más en el carácter procesal y la evaluación de aspectos subjetivos pertinentes a los aprendizajes logrados, valorando tanto los procesos como los productos y bajo referentes formativos y criterial (Román y Diez, 1992).

\section{Pero... ¿Qué es la Evaluación del Aprendizaje?}

Toda propuesta evaluativa presupone "un proceso pedagógico continuo, sistemático, participativo y flexible, que forma parte del proceso de enseñanzaaprendizaje" (Ministerio de Educación [MED], 2008, p. 51). Lo que involucra, como señalan ellos mismos, una serie de factores para sistematizar los criterios y definir los indicadores de quién es evaluado, a partir de dos funciones (MED, 2009):

- Pedagógica, al observar, recoger, analizar e interpretar información relevante sobre las necesidades, posibilidades y dificultades del aprendizaje; para reflexionar, emitir juicios y tomar decisiones pertinentes y oportunas para mejorar las actividades educativas.

- Social, al acreditar las capacidades estudiantiles de desempeño de determinadas actividades en los diversos escenarios.

La siguiente figura sintetiza las múltiples aproximaciones evaluativas:

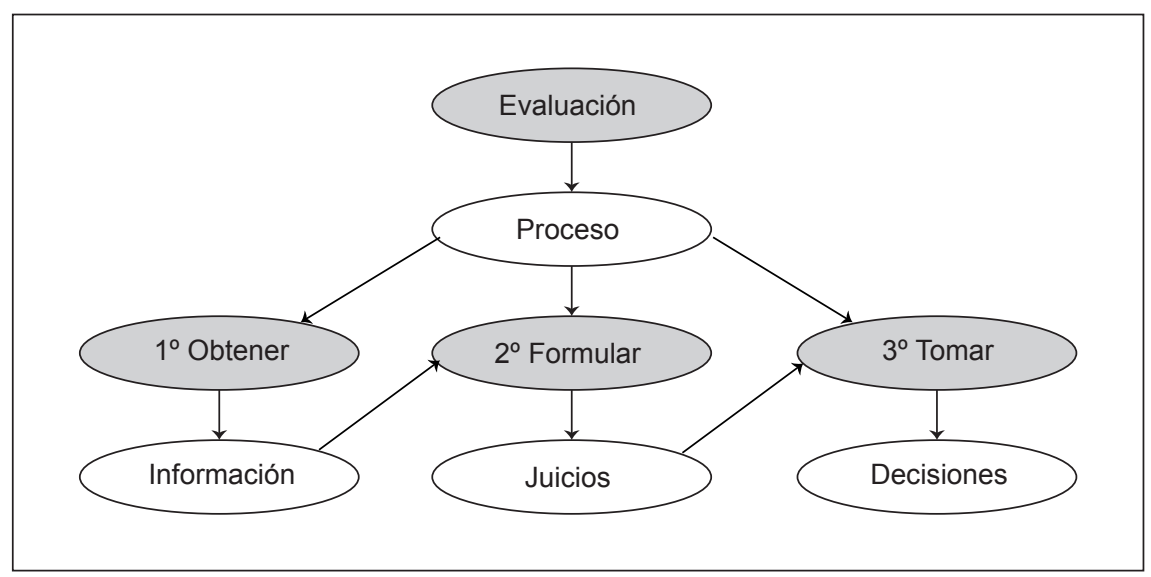

Figura 2. Estructura básica de la evaluación del aprendizaje (Castillo y Cabrerizo, 2003). 
El evaluar presupone la interacción profesor-contenido-alumno, de fases interrelacionadas y no como acciones singulares o puntuales. Demanda considerar la multiplicidad de circunstancias, propiamente, de las dimensiones que inciden en la mirada hacia sus protagonistas y a los procesos y acciones en el desarrollo de competencias y potencialidades del educando; tomando conciencia del proceso, valorando y proporcionando ayuda en el momento requerido (Serrano, 2002).

La evaluación, como inherente a la actividad pedagógica, involucra componentes que interaccionan como un todo orgánico; condicionada por elementos personales y sociales, al tiempo que incide sobre la actividad escolar: construcción del conocimiento, relaciones profesor-alumnos, interacciones en el grupo, estrategias y situaciones didácticas, disciplina, expectativas de alumnos, profesores y padres, valoración del individuo en la sociedad, etc. En su devenir, configura el ambiente educativo; define los momentos, contextos, instrumentos, actores y demás factores; revelando sus mecanismos, procesos, etc. (Fernández, 1986).

Toda evaluación se inicia con una necesidad planteada en una demanda y, por consiguiente, un estudio de la viabilidad de ese proceso; esa es una trascendental cuestión a tenerse en cuenta, y que merece especial reflexión, puesto que se relaciona directamente con nuestras razones e intereses, de modo que

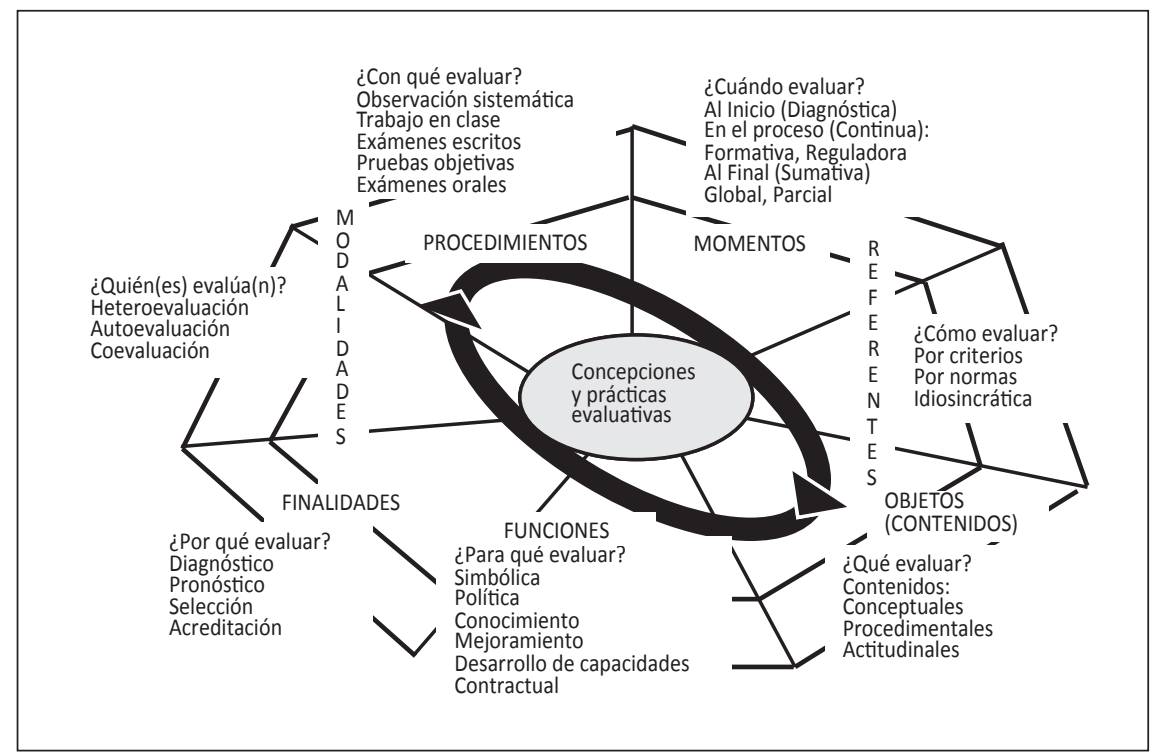

Figura 3. Dimensiones reflexivas de la evaluación del aprendizaje. 
se garantice una evaluación significativa; o sea, la "evaluabilidad" de un objeto, sujeto, proceso o situación demandada y plenamente identificada. En ese cometido, cumplen un rol vital dado que, en definitiva, serán las concepciones y prácticas evaluativas hegemonizadas las que intervendrán para determinar su fin, alcance y la transcendencia en los procesos educativos (Turpo, 2011).

\section{Finalidades y Funciones: ¿Por Qué y Para Qué Evaluar?}

La evaluación valora los procesos y resultados evidenciados a través de la enseñanza-aprendizaje. Los fines signan los propósitos, es decir, por qué evaluamos; mientras que, a través de las funciones, se explora el rol que desempeñan para la sociedad la Institución Educativa (I.E.), el proceso educativo y las personas implicadas.

Los fines (¿por qué?) y las funciones (¿para qué?) son complementarias, no necesariamente coincidentes; pueden ser variables, aunque no reconocidas ni conscientemente asumidas, pero con existencia real y en estrecha relación con el rol de la educación en la sociedad. A través de ellos, se explora lo explícito de los objetivos y lo implícito de las ideas y acciones hegemonizadas (González y Flórez, 2000).

Las finalidades evaluativas, según Elola y Toranzos (2000), plantean:

- Diagnóstico, enfatiza la producción sistemática de información calificada con el objeto de orientar la toma de decisiones, la gestión, etc.

- Pronóstico, resalta su valor predictivo como recurso de alto potencial anticipatorio y explicativo sobre los procesos objetos de evaluación.

- Selección, destaca su uso con propósitos de selección. Por ejemplo, los exámenes de ingreso a diferentes II.EE., cuando los aspirantes superan el número de vacantes.

- Acreditación, se vincula con el valor social simbólico, subrayando las consecuencias de los resultados sobre el individuo o la institución evaluada; sea para la continuidad o la interrupción de los estudios, etc.

Para estas mismas autoras, las funciones evaluativas pueden ser de los siguientes tipos:

- Simbólica, transmite la idea de finalización de un ciclo, se asocia con frecuencia la evaluación con la conclusión de un proceso. 
- $\quad$ Política, sirve de soporte a las decisiones; adquiere un rol sustantivo en la retroalimentación, la ejecución y el desempeño de los programas y proyectos.

- De conocimiento, se identifica como herramienta que amplía la comprensión de los procesos complejos.

- De mejoramiento, orienta la toma de decisiones de mejora de los procesos o fenómenos objeto de la evaluación, posibilitando una mayor comprensión de los componentes presentes.

- De desarrollo de capacidades, contribuye al desarrollo de dispositivos técnicos institucionales valiosos y pocos estimulados habitualmente.

- Contractual, explicitan y conforman el "contrato pedagógico" subyacente. Representa lo que el docente espera de esa relación y marca lo que cada uno de los alumnos está dispuesto a invertir en ella.

\section{Tipo de Contenidos y Procedimientos: ¿Qué y Con Qué Evaluar?}

La delimitación del objeto evaluativo (¿qué?) es un asunto central, de ella derivan las decisiones sobre los medios evaluativos (¿con qué?). El objeto de evaluación puede ser variado, depende del propósito; puede ser el proceso en su conjunto o algún componente del proceso: alumnos, docentes, planes, estrategias didácticas y recursos, clima educativo, etc. (Caña, Cardozo, Castillo, Caldera, Fuenmayor y Marcó, 2007). Básicamente, el objeto de aprendizaje lo constituyen los contenidos y capacidades concretadas por los estudiantes:

- Contenidos conceptuales (declarativos): es el ámbito más conocido, con la evaluación de la información se incluye además a los conocimientos previos. En tal proceder, la evaluación se orienta a evaluar la información sobre los datos o hechos declarados, como:

- las tareas de evocación o recuperación de una información sin proporcionar indicios que faciliten el recuerdo, y

- las tareas de reconocimiento de un dato, presentando varias alternativas de respuesta, y elegir la correcta.

- Contenidos procedimentales (habilidades): los procedimientos son un conjunto de acciones, formas de actuar y de resolver tareas. Son conocimientos referidos al saber hacer cosas o sobre las cosas (Coll, Pozo, Sarabia y Valls, 1992). Comprenden las actuaciones para resolver problemas, llegar a los objetivos o metas, a la satisfacción de propósitos, y el logro de 
aprendizajes. Evaluar la significatividad del aprendizaje de procedimientos es constatar su funcionalidad (Mauri y Gómez, 1991) para construir un bagaje cultural y desarrollar el trabajo intelectual.

- Contenidos actitudinales (valorativos): las actitudes poseen un componente valorativo, constituyen la cristalización de los valores asumidos. Corresponde a la escuela ser artífice de su adquisición, sea por medios conscientes (formativos) o no conscientes (interpersonales). Las actitudes son pensamientos o sentimientos hacia cosas o personas que le gustan o disgustan, le atraen o repelen, le provocan confianza o no (Sarabia y Zarco, 1997). Se conocen o creen conocerse las actitudes al reflejarse en el hablar, en el actuar, en la relación con los demás.

El con qué evaluar implica la utilización de determinadas técnicas e instrumentos de evaluación para recoger información (instrumentos) e interpretar y analizarlos (técnicas) (Gonzáles y Pérez, 2003). Seleccionar información exige una reflexión previa sobre lo adecuado. Implica no reducirse a constatar resultados, sino a ampliarlos, aportando información pertinente y elementos de análisis.

Las técnicas e instrumentos evaluativos resultan imprescindibles en una evaluación sistemática, coherente y eficaz (Escamilla y Llanos, 1995) (ver Tabla 2).

Los procedimientos evaluativos posibilitan un proceso reflexivo sobre el evaluar, considerando que no termina luego de una evaluación parcial (solo se consigna la nota obtenida); al contrario, es allí donde recién comienza, lo que invita a idear estrategias que retroalimenten el proceso, aprovechando los resultados de una evaluación integradora en la aprehensión de las capacidades del desempeño futuro (Vincensi y Angelis, 2008).

\section{Referentes: ¿Cómo Evaluar?}

Los referentes insinúan los procesos de comparación de lo que se pretende evaluar (Rodríguez, 2003); es decir, las ejecuciones del alumno con algún tipo de referencia: a) autorreferencia (respecto de las propias realizaciones) o b) heterorreferencia (las realizaciones determinadas por factores externos al alumno).

La utilización de uno u otro referente evaluativo se justifica por los objetivos pretendidos. El normativo y el criterial son los más considerados por los docentes. La norma mantiene una mayor rigidez a diferencia del criterio, que es más flexible. 
Tabla 2

Técnicas e Instrumentos de Evaluación del Aprendizaje

1. Observación sistemática 1.1. Registro de incidentes significativos. Anecdotarios

1.2. Listas de cotejo o de control

1.3. Escalas de calificación

1.4. Cuestionarios

2. Trabajos en clase

2.1. Cuadernos de clase

2.2. Debates, presentaciones, salidas a la pizarra, preguntas, etc.

2.3. Trabajos de los alumnos

2.4. Grabaciones en video o en audio

2.5. Cualquier actividad de enseñanza o aprendizaje

\section{Exámenes escritos 3.1. Preguntas de desarrollo de un tema}

3.2. Preguntas de respuestas breves

\section{Pruebas objetivas}

4.1. De respuesta única y de completar

4.2. De verdadero-falso; sí-no; etc.

4.3. De elección múltiple

4.4. De ordenación

4.5. De agrupación de parejas

5. Exámenes orales

5.1. Exposición de un tema

5.2. Exposición y debate

5.3. Entrevista

Nota. Fuente: Castillo y Cabrerizo (2003).

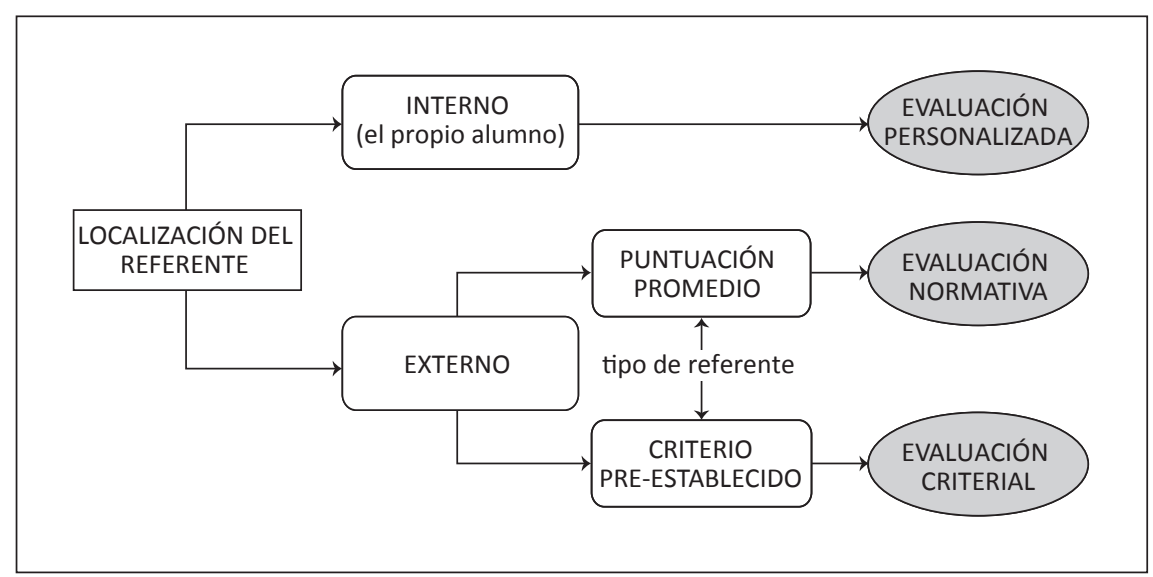

Figura 4. Tipo de evaluación según el referente (García, 1989). 


\section{Momentos: ¿Cuándo Evaluar?}

El cuándo evaluar circunscribe los periodos evaluativos. Cabe distinguir tres lapsos distintos, aunque suelen actuar complementariamente:

- La evaluación inicial (previa): ocurre en la apertura del proceso de enseñanzaaprendizaje. Su meta es determinar el grado de preparación del alumno previo al nuevo aprendizaje, pronosticando dificultades y aciertos previsibles (diagnóstica; Rosales, 1988). Se adecua a los conocimientos previos y necesidades, al tipo de ayuda más adecuada para acceder a un nuevo aprendizaje. Demanda conocer cómo se resolvió la fase anterior, cuáles son los esquemas de conocimiento, su actitud, interés, nivel de competencia curricular, etc.

- La evaluación procesual (continua): ofrece información permanente, al controlar lo planificado (avance previsto); o si, por el contrario, aparecen desvíos que los desvirtúan, obliga a su reconducción. Es formativa, al detectar cuándo se produce una dificultad, las causas que la provocan y los correctivos a introducir, estipulando de acuerdo con el nivel de aprendizaje, y concretar los aspectos aún no dominados (Bloom, Hastings y Madaus, 1971); es una comprobación sistemática sobre los resultados previstos, adecuándola en función de los logros (Lafourcade, 1977). Y, es reguladora, mostrando no solo los resultados del proceso, sino los cambios que la realidad demanda (Gairin, 2009); o a la inversa, asegurando su ajuste a las personas a las que se dirige.

- La evaluación final (confirmatoria): determina si el aprendizaje ha sido logrado o no, y es el punto de partida para una nueva intervención. Toma datos de la evaluación formativa obtenidos durante el proceso y añade otros más puntuales. Explora los objetivos al término del periodo instructivo. Tiene una función sancionadora, en la medida en que ayuda a decidir el aprobado o no aprobado de un determinado grado de estudios, área curricular, titulación, etc. (Castillo y Cabrerizo, 2003).

\section{Modalidades: ¿Quién(es) Evalúa(n)?}

Es la fase de dinamización de los agentes y sujetos evaluadores (aunque la realidad del ejercicio docente privilegia al profesorado):

- Heteroevaluación: los evaluadores y los evaluados no son las mismas personas. Se lleva a cabo dentro del centro, por el propio personal y sin la 
concurrencia de evaluadores externos (el profesor es quien evalúa a sus alumnos o la institución evalúa en concreto algunos aprendizajes; Castillo y Cabrerizo, 2003).

- Autoevaluación: los evaluadores evalúan su propio trabajo. Las responsabilidades del evaluado y del evaluador (alumno-docente) coinciden en la misma persona. La autoevaluación regula el autoaprendizaje y la autoenseñanza (Casanova, 1998).

- Coevaluación (interevaluación): evalúan determinadas personas o grupos pertenecientes a un aula, es decir, evaluadores y evaluados intercambian su papel alternativamente; propiamente, consiste en una evaluación entre pares (Delgado, 2009).

\section{Concepciones y Prácticas Evaluativas de los Docentes}

El pensar y actuar docente en los intercambios educativos incluye diversas tareas: a) planificación de su intervención, reacción ante las exigencias imprevistas o no, ante las interrupciones y el rechazo; b) el modo de reflexionar sobre su práctica y de evaluar su comportamiento, y c) los efectos de todo el proceso en el grupo y en cada estudiante en particular (Pérez, 1995). Estas dependen de los conocimientos y la experiencia acumulada; sus interacciones son el sustrato vital que incide en las concepciones y prácticas docentes.

En la socialización profesional, el profesorado forma sus discursos y rutinas sobre el alumno, el aprendizaje, la evaluación, el área curricular, etc.; definiendo la "forma de intervención" docente e interacción en el aula, en el centro y su entorno.

Ahora bien, ¿cómo se forman y adquieren las concepciones y prácticas docentes y qué factores condicionan su pervivencia? Responder a estas interrogantes abre a otras: ¿son los pensamientos pedagógicos los que dominan la actuación docente?, o ¿ son las prácticas las que dirigen las ideas docentes? Para la línea del pensamiento y la acción, las concepciones y prácticas coexisten a través de interacciones mutuas, no regidas por una causalidad sino por la interrelación instituida dentro de un marco concreto (el entorno escolar; Shavelson y Stern, 1983). Las ideas y hechos de los docentes reflejan una determinada visión epistemológica, "juegan" un papel estructurador, bloquean o dinamizan, fragmentan o integran parcelas de su conocimiento profesional (Porlán, Rivero y Martín, 1997).

La complejidad de la evaluación comporta en su naturaleza la interacción del pensamiento y acción, reflejando una multitud de variables y relaciones 
que inciden en su delimitación teórica y su concreción práctica. En su decurso, existen relaciones no unívocas sino biunívocas, en continua interacción de factores, configurando un todo organizado que se asume en la evaluación del aprendizaje como un proceso reflexivo, sistemático y riguroso. Estas ideas y prácticas han evolucionado, identificándose con la medida, adecuación a objetivos, análisis de procesos, respuesta a usuarios, instrumento para la toma de decisiones, etc., planteando su convivencia en la diversidad (Mateo, 2000).

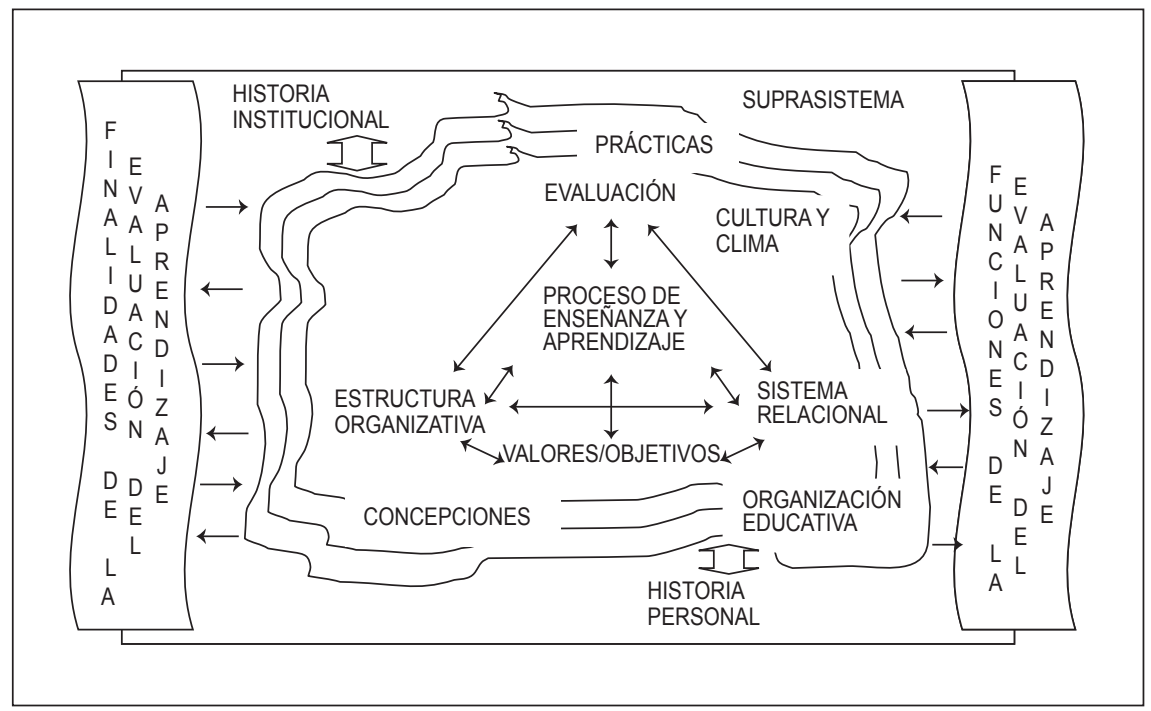

Figura 5. Elementos para el análisis de la dinámica evaluativa (adaptado de Castillo, 2002).

El esquema representa los diversos componentes (objetivos, estructuras de organización y sistema de relaciones humanas) y dinámicas organizativas (actuación de directivos y procesos que se aplican) que conforman el entramado de relaciones formales e informales de carácter sistémico y ecológico que hace incoherente cualquier estudio individual de los elementos de una organización educativa en consideración a la dinámica evaluativa (Castillo, 2002).

Las concepciones y las prácticas protagonizadas por los docentes en la dinámica evaluativa, comprenden:

- Una estructura mental subyacente

- Un modelo explicativo

- Una génesis individual y social (Giordan y Vecchi, 1988). 
Actúan como procesos que devienen de una actividad de construcción mental de lo real. Su elaboración se efectúa a partir de las informaciones grabadas en la memoria, y resultan de los sentidos y las relaciones con los otros. Luego, se codifican, organizan y categorizan dentro de un sistema cognitivo global y coherente, según las inquietudes y usos que hace cada cual; sea para completar, limitar o transformar, originando nuevas concepciones y prácticas.

En general, son constructos difusos y difíciles de operacionalizar. Constituyen representaciones de la realidad con suficiente validez y credibilidad para guiar las intervenciones docentes; se forman tempranamente, tienden a permanecer aun ante fuertes contradicciones lógicas, creando un filtro a través del cual los fenómenos son interpretados y la información procesada (Pajares, 1992).

Los profesores, frecuentemente, no somos conscientes de nuestras concepciones y prácticas y, además, estas permanecen estables a pesar de la subsecuente formación; las aparentes contradicciones suscitadas se explican a partir de la falta de conciencia de las mismas: sin reflexión ni revisión de los propios marcos de referencia. Es en la evaluación donde se revela su punto crítico; en algunas ocasiones, las prácticas que lleva a cabo contradicen sus convicciones, o sus propias ideas no son plasmadas coherentemente en su realización fáctica.

Su interacción no se entiende como causal o mecánica, sino que se explica siguiendo la "metáfora del embudo", según la cual los profesores, padres y los demás son comparables a un embudo en el que caen una serie de ideas, siendo el resultado un escaso número de acciones (Sigel, 1986). En el plano de la evaluación, estaría dado por todos los marcos interpretativos y aplicativos sobre el recojo de la información, la formulación del juicio y las posteriores decisiones; tan entremezcladas entre sí, que resulta complejo identificar una determinada prevalencia, por su carácter interactivo. Son producto de una combinación (recíproca) irreconocible, sobre quién influye sobre quién, y más aun, cómo son estas interinfluencias.

En la intervención docente se encuentran impresas las huellas de su pensamiento y acción; siendo reconocibles como elemento inseparable de su hacer práctico (Carretero, 1991).

\section{Metodología de Estudio}

La investigación implicó la aplicación de un Cuestionario Docente sobre la Evaluación del Aprendizaje del área curricular de CTA (CDEA-CTA/2010) a 
235 profesores del área de CTA; muestra representativa calculada a partir del universo de docentes (579), mediante el procedimiento de muestreo bietápico.

La selección de docentes encuestados consideró el criterio de estratificación a partir de la ubicación geográfica (distrito), el género y la edad de los docentes.

Tabla 3

Población y Muestra de Profesores del Área Curricular de CTA de la Provincia de Arequipa

\begin{tabular}{lccc}
\hline Unidad de Gestión Educativa Local (UGEL) & Población & Muestra & $\%$ \\
\hline Arequipa Norte & 259 & 103 & 44,7 \\
Arequipa Sur & 288 & 115 & 49,7 \\
La Joya & 34 & 13 & 5,6 \\
Total & 579 & 231 & 100 \\
\hline
\end{tabular}

Nota. Fuente: Gerencia Regional de Educación Arequipa (2009).

Dichos docentes laboran tanto en II.EE. de Gestión Pública Directa como de Gestión Pública Privada (de convenio)²; situados en los ámbitos urbanos, urbano-marginales y rurales de la Provincia de Arequipa (UGEL Arequipa Sur, Arequipa Norte y la Joya) ${ }^{3}$.

\section{Análisis de Resultados}

Se ha organizado la información de modo tal que posibilite una aprehensión de los aspectos fundamentales propuestos en los supuestos investigativos que orientan el estudio.

\section{Sobre la Muestra Estudiada}

Su descripción se ajusta a las variables situacionales analizadas:

2 Denominaciones utilizadas en los documentos de gestión de la Gerencia Regional de Educación de Arequipa.

1803 Mayores detalles al respecto se pueden encontrar en la tesis doctoral de Turpo (2011). 


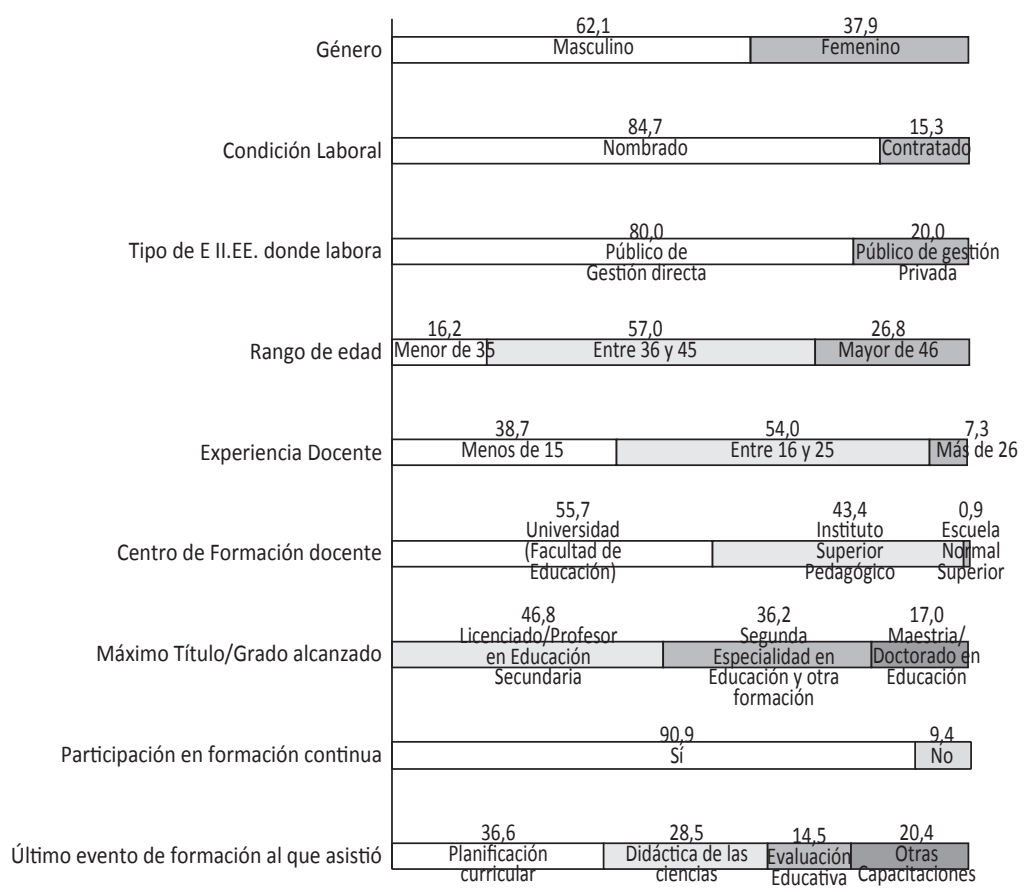

Figura 6. Perfil socioprofesional de los docentes encuestados (\%).

Por género, los docentes varones son mayoría, respecto de las docentes mujeres; están en una relación aproximada de 2 a 1 . Considerando la condición laboral, los nombrados representan al grupo predominante.

Los docentes encuestados laboran mayormente en II.EE. públicas de gestión directa, más que en las de convenio. Por edad, se distribuyen, mayoritariamente entre los 36 y 45 años de edad $(57,0 \%)$, configurando un profesorado de mediana edad, y en la etapa más productiva del ejercicio docente.

Este colectivo acumula una probada experiencia docente, superior al tercer quinquenio, indicativa del ejercicio pedagógico atesorado por los docentes que laboran en el sector público de la provincia de Arequipa.

Considerando la máxima titulación pedagógica lograda, se observa la prevalencia de los(as) licenciado(as) y profesores(as) en Educación Secundaria, y más de la mitad tienen estudios de posgrado u otras formaciones profesionales. La encuesta revela que los docentes, declaran mayoritariamente que se 
formaron en una universidad (55,7\%); y algo menos en un instituto superior pedagógico $(43,4 \%)^{4}$.

Los datos permiten apreciar el alto nivel de implicación docente en la formación continua donde, de cada 10 docentes, 9 asisten a los eventos programados. Las razones de intervención son múltiples, lo mismo que las ausencias. Los docentes que participan en eventos de capacitación docente se inclinan mayoritariamente, por la planificación curricular y la didáctica de las ciencias, eventos relacionados con su quehacer pedagógico; en ambos, se abordan cuestiones de enfoque, orientaciones metodológicas y criterios de evaluación. Quienes optan, específicamente, por la evaluación educativa, representan un escaso 14,5\%. En suma, la preferencia docente en formación continua transita prioritariamente por aspectos curriculares y didácticos.

\section{Sobre las Concepciones y Prácticas Evaluativas de los Docentes}

La dinámica evaluativa es un proceso presente en toda actividad humana; de una u otra manera, regula y coexiste en ese acontecer. En cualquier decurso de la vida, la toma de decisiones se funda en los resultados de la valoración realizada.

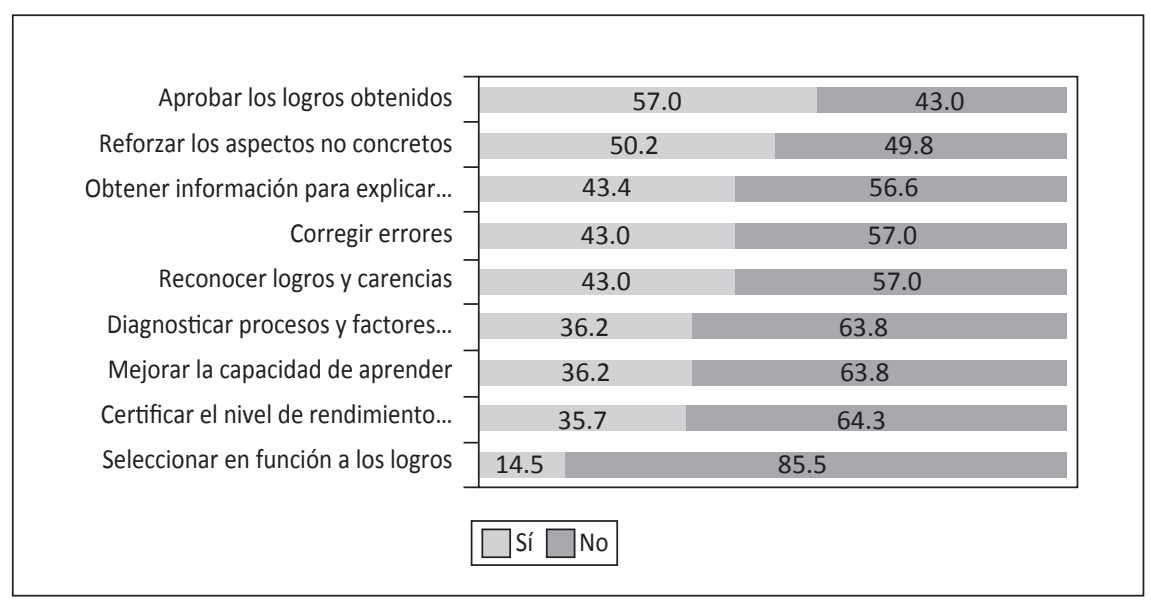

Figura 7. Finalidades evaluativas.

$4 \quad$ Un aspecto a tenerse en cuenta es que gran parte de los docentes, adicionalmente a la formación recibida en un Instituto Superior, concurren a la universidad a realizar estudios complementarios (Bachillerato en Educación) para continuar estudios de posgrado (Maestría y Doctorado). De ahí, la mayor identificación con la universidad como centro de formación docente. 
En ese cometido, las finalidades evaluativas posibilitan explorar lo explícito de los objetivos y lo implícito de las ideas y acciones hegemonizadas en el acto educativo. Propiamente, los docentes revelan una diversidad de fines promovidos.

En el plano de la acreditación, para los docentes prima "aprobar los logros obtenidos" en un 57\%; seguida de "certificar el nivel de rendimiento académico", en menor valor (35,7\%), subrayando el valor simbólico de la evaluación, resaltando su propósito utilitario y su valoración a través de la nota o calificativo asignado al aprendizaje de sus estudiantes.

Con carácter de pronóstico se busca "reforzar los aspectos no concretados" en 50,2\%; "corregir errores", en 43,0\% y "mejorar la capacidad de aprender" en $36,2 \%$; indicando la tendencia explicativa de para qué se evalúa, sus presagios tienden a retroalimentar, corregir y mejorar el aprendizaje; y a estas decisiones, los docentes le asignan una considerable importancia.

Dentro del diagnóstico, prevalecen "obtener información para explicar resultados" en un 43,4\%; "reconocer logros y carencias", en 43,0\%; y "diagnosticar procesos y factores pertinentes", en 36,2\%, lo que revela el escaso énfasis docente en la búsqueda de información para tomar decisiones pedagógicas. Y siguiendo propósitos selectivos, se opta por "seleccionar en función a los logros" (14,5\%). Una opción casi descartada por los docentes, evidenciando su poca consideración, por su carácter discriminatorio.

Las distintas finalidades evaluativas "no necesariamente se plantean como excluyentes pero sí determinan opciones metodológicas diferenciales" (Elola y Toranzos, 2000). En ese sentido, la preferencia mayoritaria por acreditar implica vincular los fines evaluativos con el valor simbólico asignado por la sociedad, a través de la escuela; enfatizando en las consecuencias de los resultados, vía la certificación acreditativa de los logros; reconociendo en los estudiantes su progresión en los estudios, como aprobado o desaprobado en el área; signando a la evaluación del aprendizaje con constatar el logro de las competencias y saberes alcanzados como consecuencia de su participación en las actividades de enseñanza-aprendizaje; y a la efectividad y eficiencia de la I.E. como prestadora de servicios a la sociedad (Valenzuela, 2004).

De ese modo, los docentes valoran las distintas finalidades de los aprendizajes logrados por sus alumnos, marcando la impronta de los propósitos que signan esa evaluación.

Se entiende por función evaluativa a los diversos procesos subyacentes al conocer, comprobar, tomar decisiones, etc. durante un acto valorativo; propiamente, se tornan en reales, en cuanto se toma conocimiento de sus resultados, 


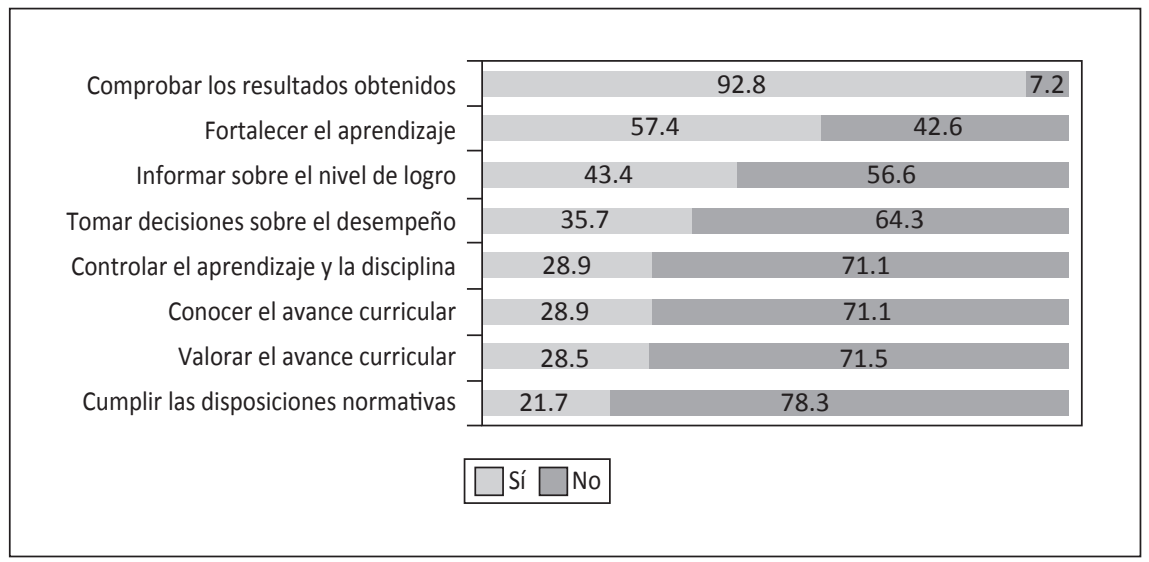

Figura 8. Funciones evaluativas (\%).

planteando una diversidad de razonamientos no solo pedagógicos sino también éticos. En ese devenir, los docentes se posesionan en torno a sus preferencias evaluativas, revelando sus interpretaciones sobre el para qué evaluar.

Considerando el carácter simbólico de la función evaluativa, se decantan por "comprobar los resultados obtenidos" en un 92,8\%; evidenciando el carácter de culminación de un ciclo, de terminación de un acto educativo, que los docentes prefieren en forma muy amplia.

En la función política, se pretende "fortalecer el aprendizaje" en 57,4\%, y "cumplir las disposiciones normativas" en $21,7 \%$. Implica en la intelección docente que lo políticamente correcto es manifestar la opción por la mejora al fortalecerla; y, lo contrario, es denigrar las normas establecidas. Un juego moral complejo, por el que se obvia lo prescrito y se justifica a través de una cuestión lógica, se trata propiamente de una subestimación de lo regulado.

Reforzando este posicionamiento, la opción por la mejora de la evaluación se traduce en un $43,4 \%$ al "informar sobre el nivel de logro", y un $35,7 \%$ al "tomar decisiones sobre el desempeño". Sus opciones refuerzan lo expresado en el párrafo precedente. Los docentes, aunque manifiesten en otros planos su preferencia por el mejoramiento, en la realidad lo consideran escasamente.

En esa misma línea, la evaluación como conocimiento es pensada para "conocer el avance curricular" en un $28,9 \%$ y para "valorar el avance curricular" en $28,5 \%$; señalando el escaso valor asignado a esta función evaluativa por los docentes. 
Y, finalmente, como función de desarrollo de capacidades, "controlar el aprendizaje y la disciplina" en $28,9 \%$, complementa la escasa valoración que se asigna a casi todas las funciones descritas por Elola y Toranzos (2000) que, con excepción de la función simbólica, sería la única altamente considerada por los docentes.

Esta claridad en las funciones evaluativas posibilita llevar a cabo los procesos educativos con oportunos resultados, sin distorsionar la realidad (Moreno, 2002). Por el simbolismo otorgado a la comprobación de los resultados obtenidos, significa reconocer que "los docentes [fundamentalmente] sintetizan y concretizan aquello que buscan consolidar en sus alumnos: conocimientos, habilidades cognitivas, destrezas, imágenes de ciencia, actitudes, trasformación conceptual, entre los principales aspectos" (López y Rodríguez, 2007, p. 3509), como evidencia del trabajo realizado a la terminación de un periodo académico.

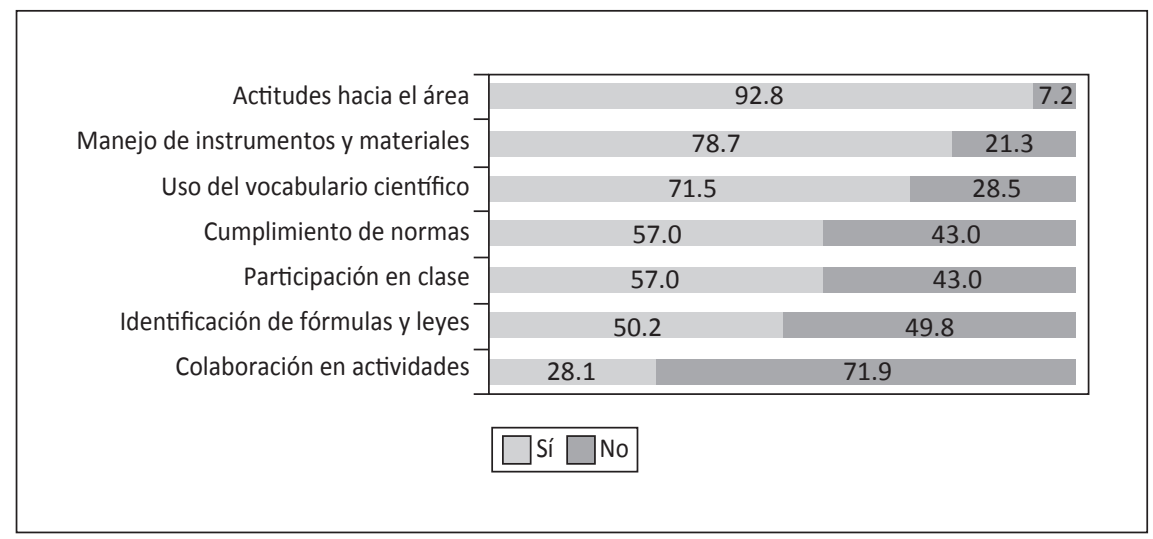

Figura 9. Contenidos evaluativos (\%).

Los contenidos responden a la interrogante ¿qué evaluar?, es decir, qué objetos son susceptibles de valoración en las ciencias. Los contenidos, como los objetos, son variados y dependen de cómo se evalúa.

En el área de CTA, los docentes expresan su deferencia respecto de los distintos tipos de contenidos curriculares: declarativos, procedimentales y actitudinales, de la siguiente manera:

Sobre los contenidos actitudinales, que incluyen a los valores, conductas, etc., asumen las "actitudes hacia el área" en 92,8\%; el "cumplimiento de normas", en 57,0\%; la "participación en clase", en 57,0\%; y la "colabora- 
ción en las actividades", en $28,1 \%$. Para estos docentes, lo importante es la disposición para aprender ciencias, exigiendo intervención y acatamiento, pero escasamente solicitan cooperación. Estos componentes demandados "cojean", pues sus "patas" no están equilibradas, por lo que se revela que, en realidad, no es tanta la preeminencia evaluativa de lo actitudinal sobre los demás contenidos, sino una somera ilusión de la apariencia de un cambio, algo así como un movimiento "gatopardista" (todo cambia para que todo siga igual).

En torno a los contenidos procedimentales, relacionados con el saber hacer, señalan su uso en el "manejo de instrumentos y materiales" en 78,7\%; esto es fundamental en las ciencias, por cuanto aportan a la resolución de problemas y ejercicios.

Considerando los contenidos conceptuales, se decantan por el "uso del vocabulario científico" en $71,5 \%$ y la "identificación de fórmulas y leyes" en $50,2 \%$. Estas menores opciones por el saber llevaron a reflexionar que habían sido relegadas por lo valorativo, lo cual, como se constató líneas atrás, no es así, sino una quimera. Los conocimientos declarativos siguen prevaleciendo como contenido preferido en la evaluación.

La evaluación de los tipos de contenido guarda sinergia con las competencias que el estudiante debe adquirir, como consecuencia de la apropiación y aplicación de los saberes y la sistematización pedagógica. Y en el análisis realizado, no se evidencia ese justo equilibrio en la evaluación, sino que persiste el predominio de lo conceptual sobre los demás tipos de conocimientos.

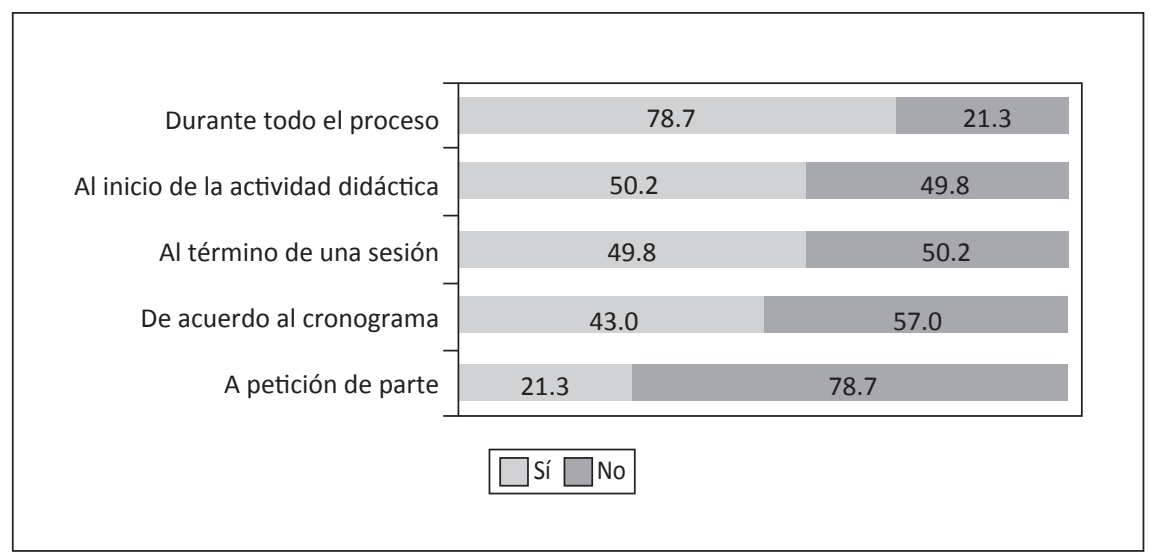

Figura 10. Momentos evaluativos. 
Los momentos evaluativos remiten a la dinámica de explorar cuándo evaluar el proceso de enseñanza-aprendizaje; en ese afán coexisten diferentes periodos para estimar los juicios valorativos sobre los logros de los estudiantes, reconociendo "la naturaleza real de su intervención y las consecuencias y efectos que produce" (Pérez y Moreno, 1998).

En ese quehacer, los docentes expresan su predilección por evaluar "durante todo el proceso" en un 78,7\%; este es un aspecto que revela el carácter formativo asignado a la evaluación, y manifiesto por el seguimiento continuo.

En segundo término, optan por evaluar "al inicio de la actividad didáctica" en 50,2\%; este tipo evaluativo es vital, pues explora el bagaje estudiantil y la predisposición para considerar lo que el estudiante aporta.

La opción por evaluar al final, esto es, "al término de una sesión", en $49,8 \%$, alude a una consideración menor, a solo asumir el carácter finalista y concluyente de la evaluación. En la misma orientación, se entiende a la elección "de acuerdo con el cronograma" en 43,0\%, una posición que discrepa con el carácter procesal de la evaluación, pues esta no está sujeta a fechas establecidas, sino que es plausible de realizar durante el proceso en sí.

La tendencia mayoritaria por la evaluación procesual señala la internalización docente de una estrategia para mejorar y fortalecer el proceso de enseñanza-aprendizaje, estableciendo criterios continuos de evaluación en la construcción de conceptos, procedimientos y actitudes (competencias) en los estudiantes; legitimando, justificando y consensuando los "instrumento para indicar en qué dimensiones se debe incidir más prioritariamente en el proceso de enseñanza y aprendizaje, orientar acerca del modo más ade-

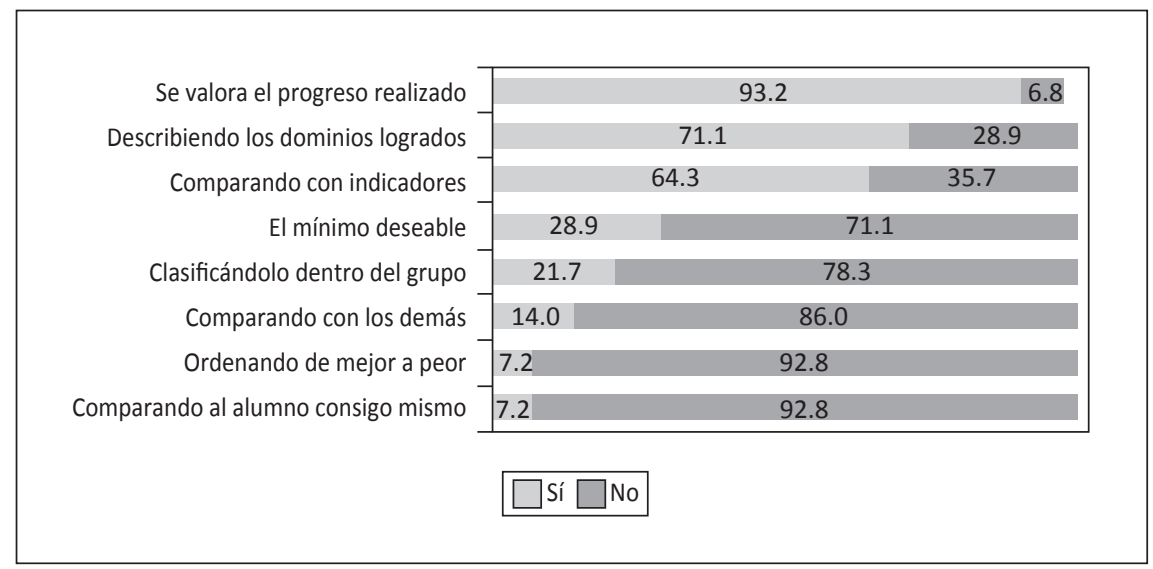

Figura 11. Referentes evaluativos (\%). 
cuado para reforzar los aspectos a tener en cuenta, y detectar los progresos alcanzados" (Bolívar, 2000).

Toda evaluación se encamina a una inevitable comparación de las ejecuciones de los alumnos respecto de algo, un referente que establece un valor de juicio sobre un alumno (Casanova, 1998); expresando su relevancia en el logro o no del aprendizaje. Considerando el normotipo (referente de comparación), la evaluación será interna o externa.

En esas intenciones, los docentes prefieren la evaluación criterial, por cuanto "se valora el progreso realizado" en un 93,2\%, el cual se realiza "comparando con indicadores" en un $64,3 \%$, resaltando así que los logros obtenidos se comparan con los criterios preestablecidos (indicadores de aprendizaje o estándares), lo cual es una decisión apropiada, por cuanto la evaluación discurre por esos laudos.

Se inclinan menos por una evaluación normativa, "clasificándolo dentro del grupo" en un $21,7 \%$, "comparando con los demás", 14\%; y "ordenando de mejor a peor", 7,2\%. Estas decisiones sitúan en retirada al promedio como referente evaluativo, lo cual es significativo.

Eligen mucho menos la evaluación personalizada, considerando "el mínimo deseable", 28,9\%; y "comparando al alumno consigo mismo", 7,2\%, un referente evaluativo escasamente valorado y conocido en su aplicación, de ahí la mínima consideración.

La determinación de un referente evaluativo obedece a identificar bajo qué motivos interpretar la "compleja red de conocimientos interconectados con formas de concebir lo que implica enseñarla y aprenderla" (Guerra, 2006). Como es de ver, los referentes entroncan con varios aspectos de la evaluación, es un "proceso interactivo que se produce entre los involucrados en el desarrollo del proceso de aprendizaje y se inicia conjuntamente con las fases de la praxis docente que se emprenda" (Guerrero y Vera, 2008).

Razonando sobre estos presupuestos, la expectativa docente se sitúa en describir los criterios (indicadores) establecidos. Esta orientación, parece responde mejor a sus concepciones y prácticas evaluativas.

Los procedimientos evaluativos incluyen las técnicas e instrumentos utilizados en la valoración de los aprendizajes logrados, posibilitando recoger, analizar e interpretar la información.

Los docentes encuestados eligen los procedimientos atendiendo a:

Los opción de los exámenes orales, a través de las "exposiciones individuales/en grupo" en $79,0 \%$, y a las "lecciones orales" en un $77,0 \%$, como predominantes en la evaluación del aprendizaje en ciencias. 


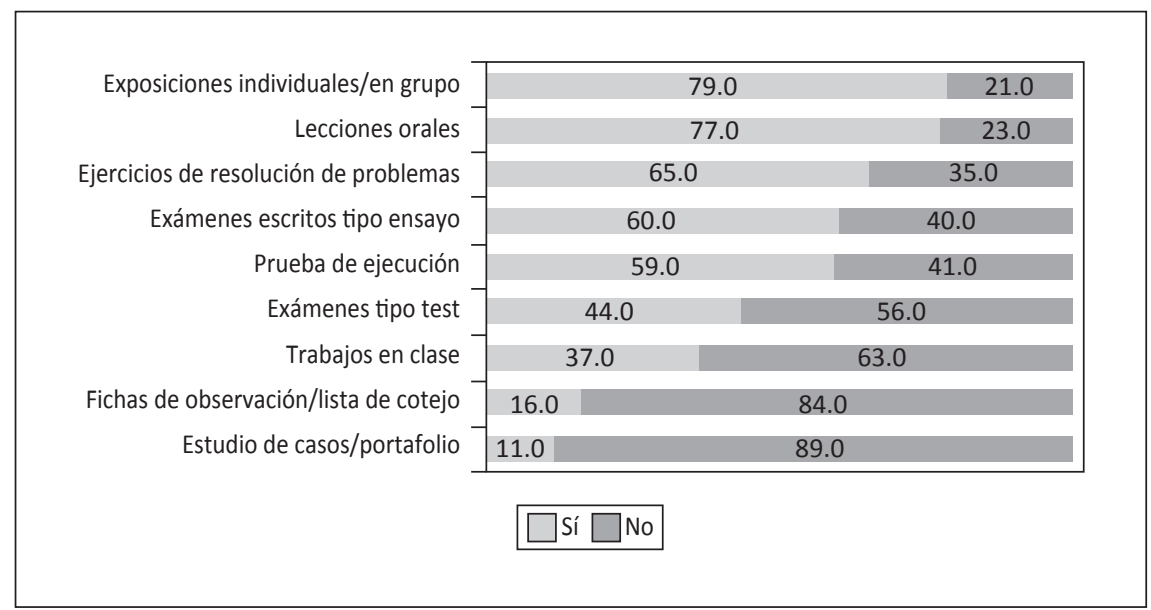

Figura 12. Procedimientos evaluativos (\%).

En una siguiente elección, prefieren los exámenes escritos, mediante los "ejercicios de resolución de problemas" en un 65,0\%; los "exámenes escritos tipo ensayo", en 60,0\%; y las "pruebas de ejecución", en 59,0\%; revelando la prevalencia de este tipo de procedimientos evaluativos.

Y en menor proporción, los "exámenes tipo test" en un 44,0\%; los "trabajos en clase", en $37,0 \%$; como procedimientos menos preferidos.

$\mathrm{Y}$ aun menor, se consideran la "lista de cotejo o escalas/fichas de observación" en 16,0\%; y el "portafolio/estudios de caso" en $11,0 \%$.

La multiplicidad de iniciativas en torno a los procedimientos evaluativos, orilla a organizar los recursos de manera flexible para resolver las determinadas circunstancias planteadas, tal que resulten útiles. La variedad y complementariedad de su uso otorga ventajas y desventajas en el proceso de registro y análisis de la información, dado que sus implicancias cognitivas y afectivo-emocionales se relacionan positivamente con el rendimiento académico (Huaney, 2010).

Se observa una priorización de los denominados instrumentos "tradicionales", es decir, de los exámenes orales y escritos y de las pruebas objetivas que dominan el universo de utilización, tratando de registrar los avances de los alumnos en los procesos referidos al saber, hacer, ser y convivir.

Como los docentes refieren, la modalidad mayoritariamente elegida es la heteroevaluación, donde la exclusividad del acto evaluativo corresponde "solo al docente", en un 71,9\%; esta es la prevalencia de una decisión hegemónica. Las expectativas siguientes, "a la institución educativa", le asignan 


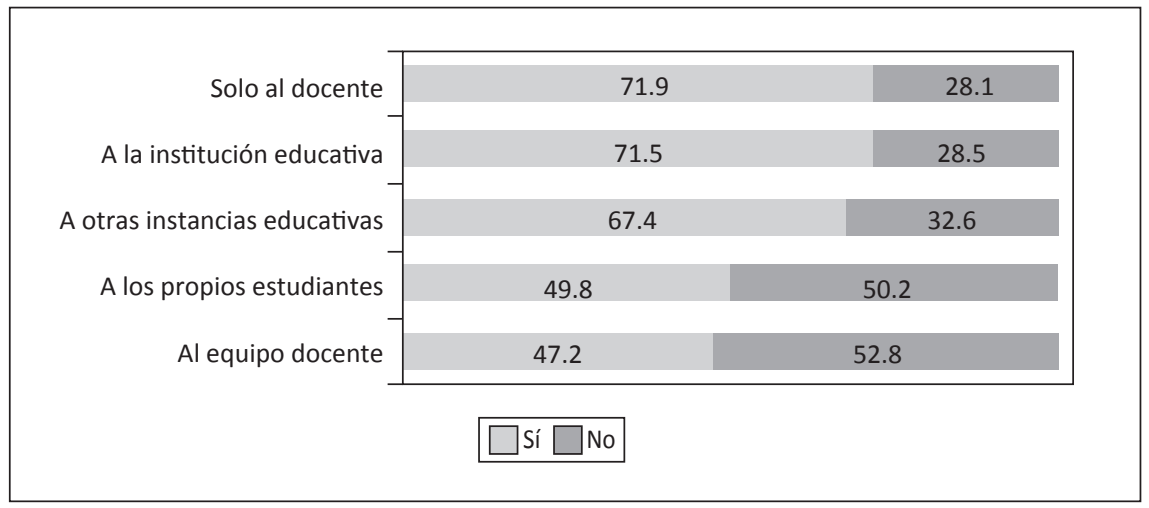

Figura 13. Modalidades evaluativos (\%).

casi similar preponderancia, un 71,5\%; y las "otras instancias educativas", algo menos, 67,4\%; son los otros protagonistas de esta modalidad evaluativa.

En menor proporción, se opta por la autoevaluación, es decir, consideran delegar la responsabilidad "a los propios estudiantes" en un 49,8\%; significando una opción no muy valorable por los docentes.

Y aun en menor proporción estiman la coevaluación, es decir, un compartir responsable con "el equipo docente", en un $47,2 \%$.

La priorización de la heteroevaluación por los agentes evaluadores es prueba del "privilegio" enarbolado en la "percepción de las características y demandas de aprendizaje más aproximada o coincidente con la información que aportan los profesores" (Pérez y Carretero, 2009). Y esto ha sido claramente apreciado en este análisis.

\section{Discusión y Conclusión de los Resultados}

Las concepciones y prácticas evaluativas de los docentes de ciencias están dentro de los procesos de mayor responsabilidad; forman parte de la "instrumentalización" de los procesos y resultados educativos, proporcionando un conocimiento "tangible" de los estudiantes. En ese devenir, elaboran de forma personal un marco comprensible de sus intervenciones, como representaciones consideradas "teóricamente más válidas" (Martín et al., 2006) y asumidos con un convencimiento más próximo a un "conocimiento correcto" que a una "operatividad real", evidenciando una actuación desconcertante; a veces, con intervenciones disonantes, contradictorias y secuelas confusas. 
Este marco referencial se organiza en esquemas que incluyen estrategias y procedimientos para la planificación, la ejecución y la evaluación educativa, los cuales son generalmente tácitos y constituidos en la mente y el discurso docente mediante principios prácticos, conocimientos, creencias, reglas, hábitos, etc. convertidos en rutinarios. Desde esa dinámica, se busca la racionalidad, atendiendo la importancia y el sentido asignado para develar sus concepciones y prácticas (Borko, 1997).

El estudio demuestra que existen concepciones y prácticas evaluativas que los docentes internalizan como muy estables y difíciles de cambiar; y otras que se encuentran en pleno cambio, pero no a grandes saltos sino de manera progresiva, detectándose distintos posicionamientos evaluativos de los profesores del área de CTA, por lo que es "posible que en un mismo profesor podamos detectar concepciones coherentes con distintas perspectivas" (Solís, Porlán y Rivero, 2005, p. 3) que van desde las consideradas como "tradicionales" hasta las "modernas" (renovadas).

Entre las orientaciones consideradas como "tradicionales", los docentes resaltan que la finalidad de la evaluación del aprendizaje es acreditar, es decir, de aprobar y certificar los logros (o sea, el rendimiento académico) de los estudiantes; en la línea de los resultados encontrados por Buendía, Carmona, González y López (1999), de registrar "los conocimientos suficientes para superar la materia y promocionar al siguiente nivel” (p. 143), relegando así el carácter formativo que contemplan los fines evaluativos. En lo que respecta a las funciones evaluativas, prevalece la dimensión simbólica, al circunscribir sus decisiones y actuaciones a la conclusión de un periodo académico, como respuesta al "cumplimiento a exigencias administrativas [...] presionados por las fechas estipuladas [y] cumplir con las notas trimestrales" (Yáñez, 2007, p. 5).

Entre las concepciones y prácticas evaluativas inscritas en la misma tendencia de las anteriores se encuentra el énfasis asignado a los contenidos ${ }^{5}$ conceptuales, generando que el resto de contenidos pivoten en torno a ellos, significando "una nueva cualidad del conocimiento: que sea 'moldeable' para que puedan aprenderlo unos alumnos concretos, ya no todo puede ser aprendido significativamente ni de la misma manera por todas las personas" (Izquierdo, 2005, p. 112).

5 Denominar a los contenidos como conocimientos resulta más pertinente, por cuanto posibilita sustentar una actividad científica escolar, motivada y con una finalidad, que se concreta en propuestas docentes temáticas coherentes e interesantes (Izquierdo, 2005). 
Dentro de los posicionamientos considerados como renovados o "modernos" resaltan la evaluación procesual como el momento evaluativo más preferido, por cuanto proporciona

[...] conocimiento de las razones de los errores y aciertos que se producen. El acto evaluativo, desde esta perspectiva, más que un proceso para certificar o aprobar, se coloca como participante, como optimizador de los aprendizajes contribuyendo a proporcionar información relevante para introducir cambios y modificaciones para hacer mejor lo que se está haciendo. (Bordas y Cabrera, 2001, p. 32)

También se decantan por una evaluación criterial, contraria a la evaluación normativa, prefiriendo el uso de criterios para indagar la situación de un individuo con respecto a un campo de conocimientos definidos (Popham, 1978), transformando secuencialmente las competencias en capacidades observables y valorables (a través de indicadores) que el estudiante ha de tener en cuenta para valorar sus acciones.

En esta tendencia, se prefieren instrumentos que evalúen, básicamente, las capacidades resolutivas y expositivas, los cambios conductuales, observables, medibles y contrastables, como los exámenes orales/escritos, sin considerar "las características personales del alumno, ni al proceso de enseñanza-aprendizaje, ni a las finalidades que se persiguen, etc." (Buendía et al., 1999, p. 149). Igualmente, se prefiere la heteroevaluación, asignando exclusiva responsabilidad a la actuación docente, limitando los espacios y tiempos del acto de evaluar, propiciando un encuentro evaluativo que no tiene nada de participativo $y$, por lo tanto, nada de democrático (Bocanegra, 2010).

Visto así, se aprecia la convivencia de dos paradigmas educativos; en un sentido, pervive un proceso pedagógico centrado en la modificación de los patrones de conducta como fundamentos orientativos, traducidos en una evaluación verificable y con resultados medibles y moldeables por reforzamientos. Esta es una contemplación antropológica y psicológicamente conductista preferida por los docentes de ciencias, asumida como "sinónimo de examen, diseñada e implementada no para cumplir con funciones pedagógicas (orientadora y retroalimentadora), sino para satisfacer necesidades burocrático-administrativas y de rendición de cuentas" (Moreno, 2009, p. 588), y como "medio que permite controlar, clasificar y seleccionar también, el acceso a las diferentes oportunidades..." (Pérez, 2007, p. 26). Y, en sentido inverso, afloran formas pedagógicas distintas de la relación con los 
protagonistas y con la multitud de medios y herramientas, en un proceso paulatino de comprensión en la acción. Estas, entienden una evaluación que toma en cuenta la singularidad del alumno, donde el acto evaluativo evidencia nociones no solo técnicas relativas a la evaluación, sino también significaciones de carácter psicológico, político, social y moral (Santos, 2001) que conducen a seleccionar determinados procedimientos evaluativos que, de una u otra forma, reflejan un conocimiento profesional y creencias y que, en definitiva, influyen en el aprendizaje y producen efectos críticos en los estudiantes (Prieto y Contreras, 2008).

En términos generales, las concepciones y prácticas docentes sobre la evaluación del aprendizaje en el área curricular de CTA están fundadas en supuestos más o menos explícitos y en usos más o menos implícitos, y asociados a discursos y rutinas pedagógicas en progresiva renovación; con manifiesta convivencia de preceptos y postulados "tradicionales" y "modernos", provenientes del conductismo y los constructivismos.

La pervivencia o persistencia de estas concepciones y prácticas evaluativas "obedecería" a los contextos situacionales, fundamentalmente a decisiones y comportamientos adquiridos en la socialización profesional. Entre estos factores incidentales estarían la orientación epistemológica de las ciencias; así, el empirismo se relacionaría con el conductismo y, a su vez, con una evaluación tecnológica o conductual.

En este proceso de indeterminaciones y convivencias mutuas, la formación continua del docente cumple rol preponderante; trasgrediendo el modus vivendi profesional del docente, suscitando la promoción de evoluciones sustanciales en apariencia pero que, en esencia, mantienen el statu quo, dado que no responden "a sus demandas profesionales ni de ofrecerles una formación suficiente para enseñar a las nuevas generaciones de alumnos" (Marchesi y Martín, 2002, p. 135).

\section{Pistas para el Debate}

Las políticas de capacitación docente, al desconocer lo que los docentes saben y hacen, los sitúan como parte del problema y no como alternativa de superación de las "tradicionales" concepciones y prácticas pedagógicas. Este "olvido voluntario" torna a la formación continua del docente en un "mero saludo a la bandera" y no en una posibilidad de renovación docente, haciendo prevalentes los factores que la condicionan. 
El reconocimiento de las concepciones y prácticas evaluativas subyacentes en los docentes de ciencias debe ser el punto de partida para (re)orientar nuevos discursos y realizaciones; generando la mutabilidad versátil y capacidad de innovar continuamente a partir de considerar la innovación docente como un salto progresivo y no como el agotamiento de lo que dice y hace el docente en su actual ejercicio pedagógico.

En el plano de la evaluación del aprendizaje, la reflexión presupone la transitividad entre el pensamiento y la acción. En ese sentido, las dimensiones de una evaluación reflexiva constituyen un círculo virtuoso de construcción perenne que se inicia y concluye en el planteamiento y revisión de las finalidades evaluativas, discurriendo sobre las funciones que desarrollen las diversas facetas educativas y sociales, precisando los contenidos en torno a los cuales se configura el conocimiento, la compartición responsable de las modalidades evaluativas en los variados momentos del hecho educativo, asumiendo distintos referentes evaluativos que vayan desde lo idiosincrático a lo criterial, y sustentándose en la diversidad de procedimientos evaluativos que exploren los diversos ámbitos formativos, sin exclusividad absolutista.

La indagación de las concepciones y prácticas evaluativas de los docentes no debe presumir, menos entenderse como obstáculos, su identificación revela potencialidades aprovechables que bien pueden servir de ejemplo, por su efectividad, como factores decisivos del éxito de una experiencia, sin concentrarse en lo accesorio o anecdótico lo que, en instancias ultimas, provoca desconciertos e incertidumbres. Por lo que resulta fundamental precisar conceptual y metodológicamente los referentes de los enfoques renovadores, a fin de no configurar escenarios de confusión terminológica, menos aun en lo sustancial. 


\section{Referencias}

Arroyo, A. (2007). Resultados de la ejecución del PLANCAD 1999-2001 en las áreas de capacitación docente y rendimiento académico de los estudiantes de los centros educativos estatales del cercado de la provincia de Trujillo (tesis doctoral). Universidad Nacional Mayor de San Marcos, Perú.

Bloom, B.; Hastings, J. T. y Madaus, G. F. (Eds). (1971). Handbook of formative and summative evaluation of student learning. Nueva York: Mc Graw-Hill.

Bocanegra, B. (2010). Evaluar preguntas y no respuestas. Perspectiva didáctica. Lima: Fondo Editorial Universidad Privada Juan Mejía Baca.

Bolívar, A. (2000). La mejora de los procesos de evaluación. Ponencia presentada en el curso La mejora de la enseñanza. Murcia: Federación de Enseñanza de Unión General de Trabajadores de Murcia.

Bordas, I. y Cabrera, F. (2001). Estrategias de evaluación de los aprendizajes centrados en el proceso. Revista Española de Pedagogía LIX, 218, 25-48.

Borko, H. (1997). New forms of classroom assessment: Implications for staff development. Theory into Practice, 36, 231-238.

Buendía, L.; Carmona, M.; González, D. y López, R. (1999). Concepciones de los profesores de educación secundaria sobre evaluación. Educación XXI, 2, 125-154.

Caña, W.; Cardozo, E.; Castillo, A.; Caldera, O.; Fuenmayor, N. y Marcó D. (2007). Evaluación de los aprendizajes. Bolívar: Universidad Nacional Experimental Politécnica Fuerzas Armadas.

Carbajal, E. y Gómez, M. (2002). Concepciones y representaciones de los maestros de secundaria y bachillerato sobre la naturaleza, el aprendizaje y la enseñanza de las ciencias. Revista Mexicana de Investigación Educativa, 7(16), 577-602.

Carretero, M. (Comp.) (1991). Procesos de enseñanza y aprendizaje. Buenos Aires: Aiqué.

Casanova, M. A. (1998). La evaluación educativa. Madrid: Muralla.

Castillo, S. (Coord.). (2002). Compromisos de la evaluación educativa. Madrid: Pearson.

Castillo, S. y Cabrerizo, J. (2003). Evaluación educativa y promoción escolar. Madrid: Pearson. 
Clark, C. (1978). Choice of a model for research on teacher thinking. Michigan: East Lansing, Institute for Research on Teaching.

Coll, C.; Pozo, J. I.; Sarabia, B. y Valls, E. (1992). Los contenidos de la reforma. Enseñanza y aprendizaje de conceptos, procedimientos y actitudes. Madrid: Santillana.

Delgado, K. (2009). Evaluación y metacognición en el aula. Investigación Educativa, 13(24), 119-133.

Domínguez, G. y Diez, E. (1996). La evaluación del funcionamiento de un centro a través del análisis de su cultura organizativa como instrumento para la mejora y la innovación. En G. Domínguez y J. Mesanza (Coords.), Manual de organización de instituciones educativas (pp. 347-404). Madrid: Escuela Española.

Eco, H. (1998). Cómo se hace una tesis. Técnicas y procedimientos de investigación, estudio y escritura. Barcelona: Gedisa.

Elola, N. y Toranzos, L. (2000). Evaluación educativa: una aproximación conceptual. Recuperado de www.campus-oei.org/calidad/luis2.pdf

Escamilla, A. y Llanos, E. (1995). La evaluación del aprendizaje y la enseñanza en el aula. Zaragoza: Edelvives.

Fernández, M. (1986). Evaluación y cambio educativo: el fracaso escolar. Madrid: Morata.

Flores, F.; Gallegos, L. y Reyes, F. (2007). Perfiles y orígenes de las concepciones de ciencia de los profesores mexicanos de química. Perfiles Educativos XXIX, 116, 60-84.

Gairin, J. (2009). Usos y abusos en la evaluación. La evaluación como autorregulación. En J. Gairin (Ed.), Nuevas funciones de la evaluación (pp. 11-44). Madrid: Ministerio de Educación y Ciencia.

García, J. (1989). Bases pedagógicas de la evaluación. Madrid: Síntesis.

Gerencia Regional de Educación de Arequipa. (2009). Padrón de Instituciones Educativas. Arequipa: Dirección de Gestión Institucional - Equipo de Estadística

Gil, D. y Martínez, J. (1999). ¿Cómo evaluar si se "hace" ciencia en el aula? Alambique, 20, 17-27.

Gimeno, J. (1998). Profesionalización docente y cambio educativo. En A. Alliaud y L. Duschtzky (Comps.), Maestros: formación, práctica y transformación escolar (pp. 131-135). Madrid: Miño y Dávila.

Gimeno, J. y Pérez, Á. (1995). Comprenderytransformarla enseñanza. Madrid: Visor. 
Giordan, A. y Vecchi, G. (1988). Los orígenes del saber. Sevilla: Diada.

Gonzáles, M. y Pérez, N. (2003). La evaluación del proceso de enseñanza-aprendizaje. Fundamentos básicos. Mimeo: Universidad Castilla La Mancha.

Gonzáles, O. y Flórez, M. (2000). El trabajo docente. México: Trillas.

Guerra, M. (2006). Los científicos y su trabajo en el pensamiento de los maestros de primaria. Una aproximación pedagógicamente situada. Revista Mexicana de Investigación Educativa, 11(31), 1287-1306.

Guerrero, W. y Vera, L. (2008). La evaluación en la praxis docente universitaria como mecanismo para asegurar la calidad. ORBIS, Revista Científica Electrónica de Ciencias Humanas, 11(4), 110-142.

Huaney, R. (2010). La función motivadora de los instrumentos de evaluación de aprendizajes y su relación con el rendimiento académico de los alumnos de la Facultad de Ciencias Sociales, Educación y de la Comunicación de la Universidad Nacional Santiago Antúnez de Mayolo (tesis de maestría). Universidad Nacional Mayor de San Marcos, Perú.

Izquierdo, M. (2005). Hacia una teoría de los contenidos escolares. Enseñanza de las Ciencias, 23(1), 111-122.

Janesick, V. (1977). An ethnographic study of a teacher's classroom perspective (tesis doctoral). Michigan State University, Michigan.

Laboratorio Latinoamericano de Evaluación de la Calidad Educativa (LLECE). (2008). Evaluación y prácticas pedagógicas en ciencias naturales. Resultados de las pruebas de CC. NN. en 6to. de Primaria. Santiago: LLECE-UNESCO.

Lafourcade, P. (1977). Evaluación de los aprendizajes. Madrid: Cincel.

Mahoney, M. (1974). Cognition and behavior modification. Cambridge: Ballinger Publishing.

Marcelo, C. (1987). El pensamiento del profesor. Barcelona: CEAC.

Marchesi, A. y Martín, E. (Comps.) (2002). Evaluación de la educación secundaria. Madrid: Instituto de Evaluación y Asesoramiento Educativo.

Marsellés, M. (2003). Actitudes y procesos de pensamiento de los profesores de la Etapa Infantil ante las diferencias de sus alumnos y sus familias. Una concepción preventiva (tesis doctoral). Universidad de Lleida, España.

Martín, E.; Mateos, M.; Martínez, P.; Cevi, J.; Pecharromán, A. y Villalón, R. (2006). Las concepciones de los profesores de primaria sobre la enseñanza y el aprendizaje. En J. I. Pozo, N. Scheuer, M. P. Pérez, M. Mateos, 
E. Martín y M. de la Cruz (Eds.), Nuevas formas de pensar la enseñanza y el aprendizaje: las concepciones de profesores y alumnos (pp. 143-159). Barcelona: Graó.

Mateo, J. (2000). La evaluación del profesorado y la gestión de la calidad de la educación. Hacia un modelo comprensivo de evaluación sistemática de la docencia. Revista de Investigación Educativa, 18(1), 7-34.

Mauri, T. y Gómez, I. (1991). La funcionalidad del aprendizaje en el aula y su evaluación. Cuadernos de Pedagogía, 188, 28-32.

Ministerio de Educación. (2008). Diseño Curricular Nacional de Educación Básica Regular. Lima: MED.

Ministerio de Educación. (2009). Diseño Curricular Nacional de Educación Básica Regular. Lima: MED.

Moreno, T. (2002). Cultura profesional del docente y evaluación del alumnado. Perfiles Educativos XXIV, 95, 23-36.

Moreno, T. (2009). La evaluación del aprendizaje en la universidad. Tensiones, contradicciones y desafíos. Revista Mexicana de Investigación Educativa, 14(41), 563-591.

Pajares, F. (1992). Teachers' beliefs and educational research: Cleaning up a messy construct. Review of Educational Research, 62(3), 307-332.

Pérez, A. (1988). El pensamiento práctico del profesor: implicaciones en la formación del profesorado. En A. Villa (Coord.), Perspectivas y problemas de la función docente (pp. 128-148). Madrid: Narcea.

Pérez, Á. (1995). La investigación educativa. En J. Gimeno y Á. Pérez, A., Comprender y transformar la enseñanza (pp. 155-134). Madrid: Visor.

Pérez, G. (2007). La evaluación de los aprendizajes. Reencuentro, 48, 20-26.

Pérez, A. y Gimeno, J. (1988). Pensamiento y acción en el profesor: de los estudios sobre la planificación al pensamiento práctico. Revista Infancia y Aprendizaje, 42, 37-63.

Pérez, M. y Carretero, M. (2009). La evaluación del aprendizaje en la educación secundaria: análisis de un proceso de cambio. Límite, 4(19), 93-126.

Pérez, M. y Moreno, J. (1998). Evaluación de dificultades en el aprendizaje de Física y Química en el segundo ciclo de la ESO. Madrid: MEC-CIDE.

Popham, J. (1978). Criterion-Referenced measurement. Nueva Jersey. Prentice Hall. 
Porlán, R.; Rivero A. y Martín, R. (1997). Conocimiento profesional y epistemología de los profesores I: teoría, métodos e instrumentos. Enseñanza de las Ciencias, 15(2), 155-171.

Prieto, M. y Contreras, G. (2008). Las concepciones que orientan las prácticas evaluativas de los profesores: un problema a develar. Estudios Pedagógicos XXXIV, 2, 245-262.

Rodríguez, J. A. (2003). La evaluación en el diseño curricular. Concepto, análisis y caracterización de la evaluación en la educación española actual. En A. Medina, J. A. Rodríguez y M. A. Sevillano (Coords.), Diseño, desarrollo e innovación del Curriculum en las instituciones educativas II (pp. 861-881). Madrid: Universitas.

Rodríguez, D. y López, Á. (2007). Conceptualización de la evaluación y su relación con el aprendizaje y la práctica docente: el caso de los profesores de ciencias naturales. Enseñanza de las ciencias [№ Extra], 3508-3513.

Román, M. y Diez, E. (1992). Currículum y Aprendizaje. Un modelo de diseño curricular de aula en el marco de la reforma. Madrid: Itaka.

Rosales, C. (1988). Criterios para una evaluación formativa. Madrid: Cincel.

Salvador, F. (1994). El profesor como mediador en el acto didáctico. En O. Sáenz (Dir.), Didáctica general (pp. 65-88). Alcoy: Marfil.

Santos, M. (2001). Enseñar o el oficio de aprender. Organización escolar y desarrollo profesional. Madrid: Homo Sapiens.

Sarabia, B. y Zarco, J. (Eds.). (1997). Metodología cualitativa en España. Madrid: Consejo de Investigaciones Sociales.

Schwab, J. (1983). Un enfoque práctico para la planificación del currículum. Buenos Aires: El Ateneo.

Serrano, S. (2002). La evaluación del aprendizaje. Dimensiones y prácticas innovadoras. Educere, 6(19), 247-257.

Shavelson, R. y Stern, P. (1983). Investigación sobre el pensamiento pedagógico del profesor, sus juicios, decisiones y conductas. En J. Gimeno y A. Pérez (Eds.), La enseñanza: su teoría y su práctica (pp. 372-420). Madrid: Akal.

Shön, D. (1992). La formación de profesionales reflexivos: hacia un nuevo diseño de la enseñanza y el aprendizaje en las profesiones. Madrid: Paidós.

Sigel, I. (1986). Reflections on the belief-behavior connection: Lessons learned from a research program on parental belief systems and teaching strategies. 
En R. Ashonore y D. Brodzinsky (Eds.), Thinking about the family: Views of parents and children (pp. 35-66). Nueva Jersey: Hillsdale.

Solís, E.; Porlán, R. y Rivero, A., (2005). ¿Qué concepciones curriculares del profesorado de ciencias en formación inicial pueden suponer un obstáculo? Ponencia presentada en XXIII Encuentros de Didáctica de las Ciencias Experimentales, Granada.

Turpo, O. (2011). Concepciones y prácticas docentes sobre la evaluación del aprendizaje en el área de Ciencias y Tecnología y Ambiente en las Instituciones Educativas de educación secundaria del sector público de la provincia de Arequipa (Perú) (tesis doctoral no publicada). Universidad Nacional Mayor de San Marcos, Perú.

Valenzuela, J. (2004). Evaluación de instituciones educativas. México: Trillas.

Vincenzi, A. y Angelis, P. (2008). La evaluación de los aprendizajes de los alumnos. Orientaciones para el diseño de instrumentos de evaluación. Revista de Educación y Desarrollo, 8, 17-22.

Yáñez, V. (2007). Concepciones de la evaluación y qué sucede en el aula. Evaluar para aprender, 1, 1-21.

Zaragoza, J. (2003). Actitudes del profesorado de secundaria obligatoria hacia la evaluación de los aprendizajes de los alumnos (tesis doctoral). Universidad Autónoma de Barcelona, España.

Manuscrito recibido: 07 de julio, 2011 Aceptado: 25 de octubre, 2011 